This preprint has been accepted for publication at Royal Society Open Science, and the open access publisher version is available at https://doi.org/10.1098/rsos.201385.

\title{
1 The relationship between mental well-being and dysregulated 2 gaming: A specification curve analysis of core and peripheral criteria in five gaming disorder scales
}

\author{
Nick Ballou ${ }^{1} \&$ Antonius J Van Rooij ${ }^{2}$ \\ ${ }^{1}$ Queen Mary University of London, London, UK \\ 2 Trimbos Institute, Utrecht, The Netherlands
}

\begin{abstract}
Gaming disorder (also known as dysregulated gaming) has received significant research and policy attention based on concerns that certain patterns of play are associated with decreased mental well-being and/or functional impairment. In this study, we use specification curve analysis to examine analytical flexibility and the strength of the relationship between dysregulated gaming and well-being in the form of general mental health, depressive mood, and life satisfaction. Dutch and Flemish gamers $(\mathrm{n}=424)$ completed an online survey containing five unique dysregulated gaming measures (covering nine scale variants) and three well-being measures. We find a consistent negative relationship; across 972 justifiable regression models, the median standardized regression coefficient was -0.39 (min: -0.54 , max: -0.19 ). Data show that the majority of dysregulated gaming operationalizations converge upon highly similar estimates of well-being. However, variance is introduced by the choice of well-being measure; results indicate that dysregulated gaming is more strongly associated with depressive mood than with life satisfaction. Weekly gametime accounted for little to no unique variance in well-being in the sample. We argue that research on this topic should compare a broad range of psychosocial well-being outcomes and explore possible simplifications of the DSM-5 gaming disorder criteria. Given somewhat minute differences between dysregulated gaming scales when used in survey-based studies and largely equivalent relationships with mental health indicators, harmonization of measurement should be a priority.
\end{abstract}

Keywords: dysregulated gaming, gaming disorder, well-being, specification curve analysis

Word count: 10033 


\section{Introduction}

Some players of video games develop a pattern of behavior in which video game use becomes dysregulated, accompanied by significant psychological distress and/or functional impairment. This phenomenon is colloquially referred to as 'gaming addiction,' but is also known as (internet) gaming disorder, dysregulated gaming, or problematic video game use. In the current work, we adopt the term dysregulated gaming; indicators of dysregulation are self-reported by respondents, but we are hesitant to assess a clinical disorder on the basis of survey data alone at this stage [1].

Over the past decades, worldwide recognition that patients sometimes present with dysregulated gaming issues has stimulated efforts to formalize the issue as a psychopathological condition in manuals. This has prominently led to the inclusion of Internet Gaming Disorder (IGD) as a condition warranting further study in the fifth edition of the Diagnostic and Statistical Manual of Mental Disorders (DSM-5) [2], and the addition of Gaming Disorder to the ICD-11 framework [3]. However, the status of dysregulated gaming as a psychopathological condition remains heavily debated [4-6]. This includes areas of uncertainty regarding measurement, comorbidity, symptomology, and more.

Concern about dysregulated gaming largely stems from the negative outcomes with which it is associated, rather than about engagement with gaming per se. As opposed to games being inherently harmful, as evidenced by the extensive literature on positive effects that can result from video game play [7], it is generally thought that certain patterns of game use may be either associated with or result in detrimental effects to other important aspects of the players' lives. Gentile et al. [8] write 'playing is not pathological initially but becomes pathological for some individuals when the activity becomes dysfunctional, harming the individual's social, occupational, family, school, and psychological functioning' (p. e320). Negative outcomes that have been linked with dysregulated gaming include psychopathology (e.g., depression or anxiety) [e.g., 9], decreased work/academic performance [10], poorer physical health [e.g., 11], lower life satisfaction [e.g., 12], and social problems [e.g., 13].

Other work, however, has not always supported these links. Some researchers have failed to find a negative relationship between dysregulated gaming and well-being [e.g., 14], whereas others have interpreted effects that they have found to be too small to be meaningful [15]. Even when negative effects are found, the causal nature of the relationship has been heavily debated, with some evidence suggesting that dysregulated gaming may be better understood as a symptom of an underlying disorder or disorders [6]. In sum, more evidence is needed both with regard to the strength of the relationship between dysregulated gaming and well-being, and whether this varies between different aspects of well-being.

In this paper, we use specification curve analysis in an attempt to shed light on this relationship. We compare five distinct dysregulated gaming questionnaires, encompassing nine possible measurement approaches, alongside three different well-being measures, allowing us to investigate the influence of analytical flexibility on results. We further compare core and peripheral dysregulated gaming criteria [16] and the influence of previous covariates or 'risk factors' identified in previous literature, like amount of time spent gaming and gaming motivations.

Due to the wide scope of the analyses presented here, the key findings are summarized in Box 1 as a resource for the reader. Each of these findings will be examined in more detail 
Box 1

Summary of key findings

- Dysregulated gaming scales were more similar than they were different in terms of their association with well-being, with 8 of 9 measures converging upon highly similar effect size estimates

- Dysregulated gaming was more strongly linked with increased depressive mood than with lower life satisfaction

- A peripheral DSM-5 criterion, escapism, was the strongest single-item predictor of decreased wellbeing; however, it may be confounded and assess the presence of problems in a player's daily life, rather than solely their use of games to escape problems

- The same may be true to a slightly lesser extent of escapism as a player motivation

- Although escapism was strongly predictive of well-being on its own, the inclusion of peripheral DSM-5 criteria did not meaningfully strengthen or obscure the relationship between dysregulated gaming and well-being compared to using core criteria only

- In line with other work, no meaningful relationship was found between self-reported weekly playtime and well-being

- While they remained similarly predictive of well-being, two previously-used scales (VAT and CVAT-2) were not found to be unidimensional in our sample

- Psychometric evidence supported the validity of 5 other scale variants

throughout the method, results, and discussion sections.

\section{Core vs Peripheral Criteria}

One particularly contentious aspect of dysregulated gaming research concerns the differentiation of high-engagement, non-pathological gaming from true dysregulation. Dysregulated gaming criteria have often been adapted from other behavioral addictions, particularly problem gambling. Measures developed to assess dysregulated gaming, whether based directly on the DSM-5 or otherwise, regularly include both criteria that directly assess negative consequences of gaming on a person's well-being or functioning as well as criteria that ask about a person's cognitive and behavioral engagement, but that are not inherently negative [17].

This distinction has sometimes referred to as 'core' vs 'peripheral' criteria $[16,18]$. A large body of work has shown that high engagement with games does not imply negative consequences, even for players who play dozens of hours per week. This distinction has been made on theoretical grounds, using evidence from case studies [19], latent class analysis [20], and survey work showing weaker associations psychological risk factors [e.g., 21] and functional outcomes [e.g, 22] for highly-engaged gaming than for dysregulated gaming.

Early work on dysregulated computer use used factor analysis to show that the tolerance, euphoria, and preoccupation (cognitive salience) criteria loaded onto one separate factor, referred to as engagement, while inter- and intrapersonal conflict, relapse and reinstatement, withdrawal, and loss of opportunities loaded onto a second factor, referred to as 'addiction' [23], with this distinction later being replicated for games [16]. Much work has followed from this; [24], for example, use item response theory to show that two peripheral DSM-5 criteria, preoccupation and escapism, are poor at discriminating dysregulated gamers, 
and argue for their removal from dysregulated gaming measures.

Preoccupation has been identified as a particularly problematic peripheral item, with [25] finding that the IGD salience criterion reached an endorsement rate as high as $77.3 \%$ on a dichotomized scale in their sample. A recent review article [26] identified withdrawal, interand intrapersonal conflict, unsuccessful attempts to stop (lapse/relapse), loss of control, and continuation despite problems as likely core criteria; preoccupation, tolerance, lying about use, and mood modification (escapism), on the other hand, were listed as likely peripheral criteria.

Despite general agreement that current scales conflate core and peripheral criteria, delineations of which criteria may be considered core or peripheral have not always been clear-cut. Deleuze and colleagues [25], for example, found that mood modification more closely resembled a core criterion. In this paper, we adopt a conservative position and only classify criteria directly assessing a negative consequence on the person's life (including internal psychological conflict) as a result of their gaming as core criteria (see appendix for item-wise classification).

\section{Gaming motivations and basic psychological need satisfaction in relation to dysregulated gaming}

Gaming Motivations. Significant research attention has been paid to covariates of dysregulated gaming. In particular, the motivational styles of players have emerged as a popular topic of inquiry. Hilgard and colleagues [27], for example, found that players who scored highly on three types of motivation - escapism, social interaction, and grinding - were more likely to exhibit symptoms of dysregulated gaming. Several studies have used versions of Yee's [28] Motives for Play in Online Games questionnaire, with one example finding that escapism $(\beta=.36)$ and mechanics $(\beta=.21)$ were linked with problematic video game use [29]. Billieux et al. [30] report related findings, showing that Yee's advancement, mechanics, competition, role-play, customization, and escapism motives were linked with dysregulated gaming symptoms, and that those motives also predicted particular in-game behaviors and progression over time. Another study found that entertainment/achievement, social, and escapism motives were associated with problematic gaming ( $\beta s=.19, .23$, and .30) [31]. Overall, researchers have identified a range of motives as possible risk factors for dysregulated gaming, with escapism noted as a particularly common one with conceptual implications given its overlap with a peripheral DSM-5 criterion. When studying the relationship between well-being and dysregulated gaming, it therefore seems wise to include these motivations in the analysis process to investigate their role as complementary or potentially overlapping constructs.

Self-determination Theory and Dysregulated Gaming. Self-determination theory [SDT; [32]; [33]] has emerged as a popular framework for understanding motivation to play games. One of SDT's sub-theories, Basic Psychological Needs Theory, states that activities and environments are most likely to be motivating and support well-being when they provide for the satisfaction of three needs, namely autonomy (the need to feel that one's actions are volitional and self-endorsed), competence (the need to act effectively and experience growth), and relatedness (the need to have one's authentic self accepted by others and to feel both caring and cared for). A large body of work has found that satisfaction of basic needs in video games has been positively linked with enjoyment and motivation to 
play [e.g., 34,35].

Further work has examined in-game need satisfaction in the context of dysregulation. Two studies have found that need satisfaction in games was associated with dysregulated gaming, but that both this relationship and the relationship between need satisfaction in games and well-being was moderated by need dissatisfaction/frustration in daily life [36,37]. [38] write that need satisfaction in games may operate as a risk factor, and need satisfaction in real life as a protective factor, with each operating somewhat independently. Given these findings, we include the experience of need satisfaction in video game contexts as a further covariate.

\section{Present Research}

Research on games disorder currently makes use of a wide range of questionnaires, with a recent systematic review identifying 32 existing scales with varying degrees of empirical support [17]. However, scales are rarely directly compared against each other, leaving us with an incomplete understanding of the degree to which analytical flexibility might drive results when using dysregulated gaming as either an explanatory or outcome variable. When comparisons has occurred, they have typically been done in the context of convergent validity, or the comparing a new dysregulated gaming measure with an existing one, and include only two scales [e.g., 39,40].

In the present research we extend this, focusing on the relationship between dysregulated gaming measures and mental well-being, namely general mental health, life satisfaction, and depressive mood. We use specification curve analysis to integrate results from 5 dysregulated gaming measures (yielding 9 possible specifications) and 3 well-being measures. We select and, where necessary, have developed measures to include 1) an adaptation of earlier compulsive internet use scales, 2) the DSM-5 Internet Gaming Disorder criteria, 3) the ICD-11 Gaming Disorder criteria, 4) criteria from a large-scale international project on children's digital well-being (Global Kids Online), and 5) a collaborative attempt to define behavioral addiction. Given that dysregulated gaming is expected to be linked with decreased well-being, this can also be framed as an investigation of the concurrent (criterion) validity of different dysregulated gaming scales. Our research questions are threefold:

1. What is the strength of the relationship between dysregulated gaming severity and psychological well-being?

2. How much variability in the size of that effect can be attributed to analytical choices, including the selection and operationalization of the criterion variable (dysregulated gaming severity), outcome variable (well-being), and the in/exclusion of various covariates (demographics, gaming motivations, and need satisfaction in games)?

3. Are dysregulated gaming core criteria more strongly associated with decreased mental well-being than engagement criteria?

\section{Method}

\section{Procedure}

Dutch and Flemish (Dutch-speaking Belgian) subjects were recruited between December 2018 to March 2019 to complete an online survey built in Limesurvey. Flemish 
161

participants were recruited from a gaming news website (4gamers.be), while Dutch participants were recruited through a Facebook ad campaign associated with a Public health website (gameninfo.nl); a minority of Dutch participants (7\%) joined the survey from the public health website directly. Respondents were required to be at least 16 years old and complete an informed consent form. In exchange for finishing the survey, participants were entered into a raffle for 1 of $6 € 50$ Gamegear gift certificates.

Participants completed Dutch language versions of the measures below, totaling 132 items. Measures were presented in a fixed order, with the order of items within each measure randomized. The survey sequencing was chosen to avoid the possibility of multiple consecutive negatively-interpreted measures and/or monotony by alternating dysregulated gaming scales with non-dysregulated gaming scales (e.g., demographic questions, gaming motivations, or well-being measures). Longer measures were placed toward the beginning of the survey to mitigate survey fatigue. We included 2 attention checks and a number of reverse-coded items throughout the questionnaire.

\section{Participants and cleaning}

A total of 743 people began the survey, and after cleaning we retain 424 . We remove 289 (38.9\%) people who began the survey but did not complete it. Contrary to expectations, the presentation of multiple thematically similar measures does not appear to have been the driving force for this relatively high drop-out rate; of the 491 participants who made it as far as the second dysregulated gaming measure, 454 completed the entire survey. Instead, $87 \%$ of the participants who abandoned the survey did so during the first three measures. While we cannot be sure of the cause of participant drop-out, we suspect that the slow filling of the survey progression bar after each page signaled to participants that the questionnaire was lengthier than they had expected or were willing to complete.

We additionally removed 30 participants who entered an incorrect answer for 1 or both of the 2 careless response checks [41]. This decision was corroborated by manual inspection of the data, which revealed high rates of uniform or patterned responses among these. Overall, the quality of responses for participants who completed the full survey is high; only $6.6 \%$ of the participants who completed the survey are dropped based on the careless response check, and reverse-coded items perform as expected in all scales in which they appear. This resulted in our final sample size of 424 .

Of the final participants, 220 were Dutch and the remainder were Flemish (204). The average age was $24.2(\mathrm{SD}=7.7)$. This included 307 males, 113 females and 4 participants who preferred to specify another gender. The median completion time for the survey was 14 minutes. Each item required an answer, and therefore after removing incomplete survey responses according to the procedure above, there were no missing data.

A t-test revealed that Dutch participants reported higher dysregulated gaming on average $(t[502.77]=-2.50, p=.013)$; this is likely a result of the fact that Dutch participants were significantly younger than Flemish ones $(t[378.60]=3.41, p=.001 \mathrm{M}=20.8$ vs 27.9). Given overall high similarity between the two groups (same language, high degree of cultural overlap, participants all self-selected due to interest in gaming) and no theoretical reason to expect the relationship between dysregulation and well-being to vary the two countries, we elected to analyze them together.

Further tests indicated two significant differences between participants dropped due 
to incomplete responses or careless response checks compared with the rest of the sample. Dropped participants reported on average lower educational levels $\left(\chi^{2}[1, n=424]=5.68, p=\right.$ .017) and higher scores on the first of the presented dysregulated gaming measure, the CVAT $(t[134.47]=2.22, p=.028)$. No statistically significant differences were detected for the other demographic variables, age and gender. As a result of these differences, we conducted a sensitivity analysis in which both incomplete and careless responses were included; this did not meaningfully change the pattern of results (see supplementary materials).

\section{Measures}

All measures were assessed on a 5-pt Likert scale where 1 is 'completely disagree,' 3 is 'neither disagree nor agree,' and 5 is 'completely agree.' Exact wordings for each measure can be found in the appendix. Scale scores were calculated by averaging the relevant items (after reverse coding, as necessary). In addition to the measures below, participants also reported their ambitions for digital careers (e.g., streamer or esports competitor), one or more favorite games, and commonly used devices. This data is not analyzed here.

Table 1 shows the descriptive statistics for each measure, and Figure 1 displays zeroorder correlations between all variables in the study. Descriptive statistics are reported based on the sample with outliers excluded (see Analytical Approach below). Cronbach's $\alpha$ is omitted in favor of McDonald's hierarchical omega $\left(\omega_{h}\right)$ as a measure of reliability, as the latter does not assume essential tau-equivalence (i.e., equal factor loadings) and is known to be a more appropriate estimate $[42,43]$. Values of $\omega_{h}$ can be interpreted similarly to $\alpha$ values. Reliability for the dysregulated gaming measures is reported in the factor analytic results (Table 2) below.

\section{Well-being}

General Mental Health. General mental health was measured with the 5-item Mental Health Inventory (MHI), which constitutes the mental health sub-scale of the Medical Outcomes Study (MOS) Short-Form Health Survey [44]. The MHI is well-validated, including in a Dutch sample [45], and has been used for the screening of major depression, dysthemia, as well as certain anxiety disorders.

Life Satisfaction. Participants completed the 5-item Satisfaction with Life scale [46]. This measure includes items like 'In most ways my life is close to ideal' and 'I am satisfied with my life.'

Depressive Mood (reversed). Depressive mood was measured using the 6-item Adolescent Depressive Mood scale [47]. Participants are asked the extent to which they have been bothered or troubled by tiredness, sleep problems, sadness, hopelessness, nervousness, and anxiety. To maintain consistency with the other two well-being measures (i.e., higher scores reflecting greater well-being), depressive mood scale scores were reversed, and thus are referred to here as absence of depressive mood.

\section{Dysregulated Gaming}

Video Game Addiction Test (VAT). The 14-item Video Game Addiction Test (VAT) [48] was developed as a domain-specific adaptation of the Compulsive Internet Use Scale [49]. The VAT assesses loss of control (four items, e.g., 'How often do you continue to 
use the games, despite your intention to stop?'), conflict (four items, e.g., 'How often do others (e.g., parents or friends) say you should spend less time on games?'), preoccupation/salience (three items), coping/mood modification (two items), and withdrawal symptoms (one item).

Clinical Video Game Addiction Test 2.0 (CVAT-2). The Clinical Video Game Addiction Test 2.0 (CVAT-2) [50] was developed in consultation with clinicians in the Netherlands to conform to the DSM-5 IGD criteria. It was validated on a sample of adolescents and young adults in clinical treatment for dysregulated gaming, exhibiting high sensitivity (91\%) in that sample. The CVAT-2 originally takes the form of yes/no checklist. For consistency, this scale was rephrased into statements that are answerable in the 5-pt format (e.g., "You regularly play games because you're feeling down" replaces the item "How often do you game because you are feeling down?"). There exist a 9-item and 11-item version of the CVAT-2, referred to here as CVAT-2 (9-item) and CVAT-2 (11-item). The 9-item version contains items corresponding to each of the nine DSM-5 criteria, while the 11-item version includes two additional items for craving and physical hygiene at the suggestion of therapists involved in the development of this scale. Participants completed the 11-item version, allowing for analysis of both approaches.

ICD-11. At the time that this study was conceptualized in 2018, no existing scales covered the criteria outlined for Gaming Disorder in the ICD-11 [3]. Thus, a 4-item scale was drafted based on these criteria, which both read at the time and currently read:

1. Impaired control over gaming (e.g., onset, frequency, intensity, duration, termination, context)

2. Increasing priority given to gaming to the extent that gaming takes precedence over other life interests and daily activities

3. Continuation or escalation of gaming despite the occurrence of negative consequences of sufficient severity to result in significant impairment in personal, family, social, educational, occupational or other important areas of functioning.

A fourth criterion specifies that the above behaviors should be 'evident over a period of at least 12 months.' To incorporate this, one item was generated for each of the three above criteria (e.g., 'You continuously give gaming priority over other hobbies and daily activities'), and a fourth assesses the duration of any problems ('Gaming has been problematic for you for over a year').

Global Kids Online (GKO). Participants completed the 5-item Excessive Internet Use sub-scale of the Global Kids Online (GKO) survey [51], which was collaboratively developed for use with 9-17 year olds to understand digital behavior and health. The Excessive Internet Use sub-scale contains 5 items assessing functional consequences of dysregulated use of the internet. The scale was adapted to refer to games specifically, resulting in items like 'I have gone without eating or sleeping because of the time I spent on gaming' and 'my grades have dropped because of the time I spent on gaming.'

Open Definition of Behavioral Addiction (ODBA). Next, the participants completed a 4-item scale developed for the purposes of this study based on the Open Definition of Behavioral Addiction (ODBA) $[52,53],{ }^{1}$ a collaborative effort to form a consensus definition of behavioral addictions across domains. At the time of writing, this definition reads, 'A repeated behaviour leading to significant harm or distress. The behaviour is not reduced by the person and persists over a significant period of time. The

\footnotetext{
${ }^{1}$ see also the up-to-date version maintained at https://osf.io/q2vva/
} 
harm or distress is of a functionally impairing nature' (emphasis added). To the authors' knowledge, no gaming disorder measure has explicitly adopted this definition, and so a four-item measure was drafted on an exploratory basis to assess these criteria (e.g., 'your gaming has been causing problems for you for months, but you are unable to play less.' In contrast with other scales, one item was negatively phrased: 'Gaming does not lead to problems in your daily life (such as: problems with school, work, other interests, family, or friends).' The final item assesses one of the ODBA's listed exclusion criteria, and is also reverse-scored: 'The time you spend on gaming is a conscious choice.'

Composite scale: DSM-5 (CVAT-2) \& ICD-11: CVAT-3. The data for the current study were originally collected to improve the self-test available on the Dutch public health website gameninfo.nl. This website currently makes use of a composite test that covers both the DSM-5 criteria (via the CVAT-2 11-item version) and the ICD-11 items listed above $(11+4=15$ items total $)$. The composite scale was chosen for conceptual reasons, namely to yield comprehensive coverage of the criteria in the two most prominent diagnostic manuals. Given that it effectively constitutes an expanded version of the CVAT-2, we refer to this here as the CVAT-3.

\section{Covariates}

Demographics. Participants reported their age, gender, and level of education. The latter was standardized between countries in the dataset to two levels, namely primary education/secondary education versus higher/tertiary education.

Game time. Participants provided self-report estimates of the amount of time in hours they spend playing games on an average weekday and average weekend day. These were multiplied $(5 *$ weekday $+2 *$ weekend $)$ to yield an estimate of participants' total weekly game time.

Game session duration. Game session duration was measured with a single item asking participants 'How many minutes do you game, on average, when you play (per game session)?'

Gaming Motivations. Participants completed an abbreviated version of the Digital Games Motivation Scale (DGMS) [55,56]. The DGMS is informed by Social Cognitive Theory [57] and assesses the degree to which players experience eight different identified motives for playing games. The complete DGMS is 43 items, and thus an abbreviated 24-item version is used here, containing 3 items from each of the DGMS sub-scales, which are:

- habit, playing automatically as part of a normal routine

- moral self-reflection/reactivity, playing because of expectations of meaning and value from time spent gaming

- pastime, playing games to kill time

- performance, playing to succeed or excel

- agency, playing to experience a sense of volition and play according to one's own preferences

- narrative, playing to feel a sense of involvement or believability in the game's story, world, and characters

- social playing to enact non-competitive behavior or be respected by other players, and

- escapism, playing to leave the daily routine behind and experience things not possible outside the game world 
Table 1

Descriptive statistics for explanatory, criterion, and control variables

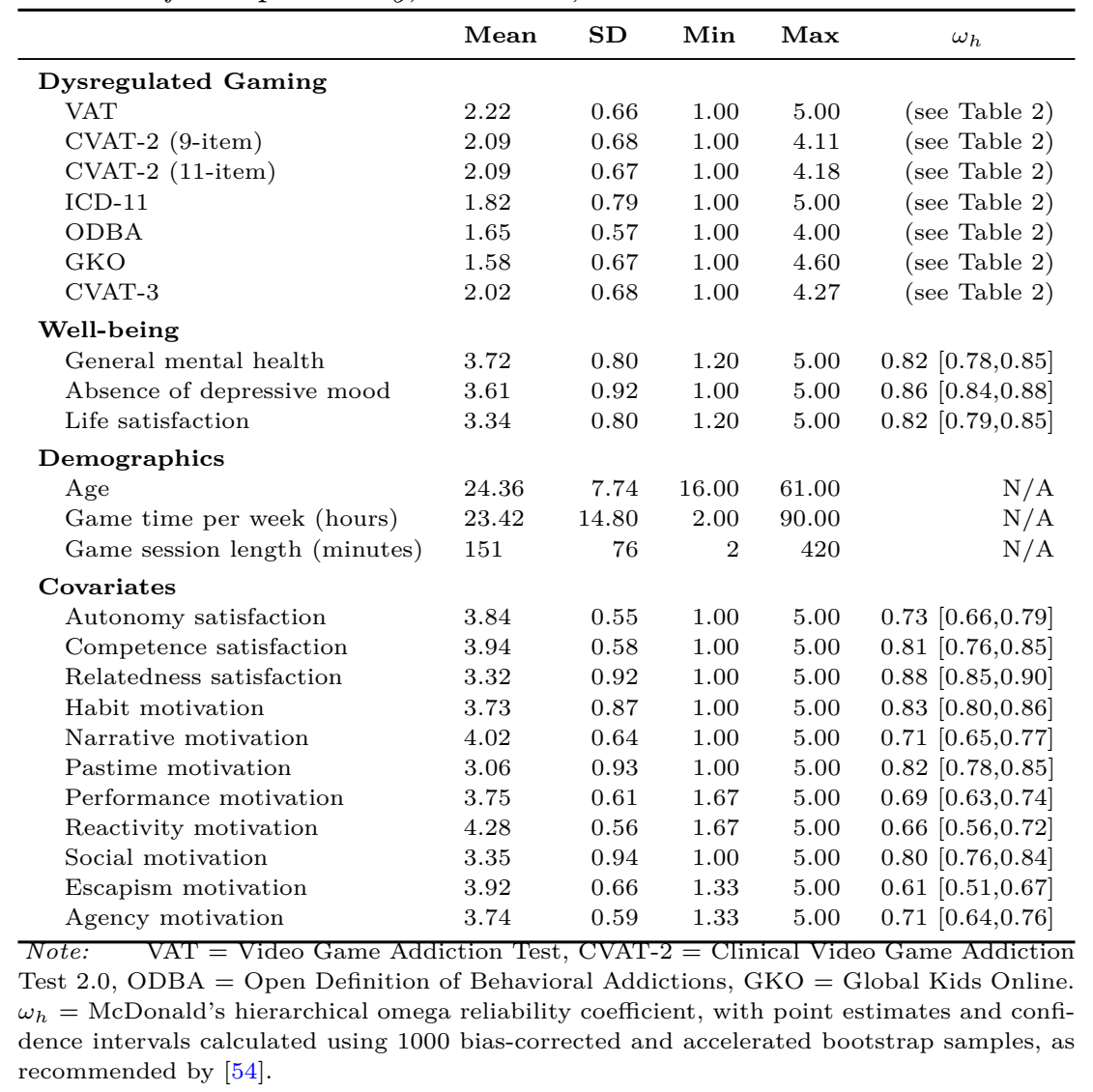

Need Satisfaction in Video Games. Last, participants completed an adapted version of the Basic Psychological Need Satisfaction and Frustration scale [58]. The adapted version was developed for use in an exercise context with a Dutch sample by [59]. Items were reworded to suit a video games context. The frustration sub-scales are not used, leaving 3 sub-scales of 4 items each: autonomy satisfaction (e.g., 'I felt that the game allowed me to do what I wanted to do'), competence satisfaction (e.g., 'I was confident that I was skilled enough to play the game well'), and relatedness satisfaction (e.g., 'I felt close and connected to one or more players in-game').

\section{Analytical Approach}

We adopt specification curve analysis (SCA) [60] as our approach for examining the correlation between the explanatory (gaming disorder severity) and criterion variables (psychological well-being). This type of analysis is well-suited to a dataset like the one at hand in which the presence of multiple similar measures allows for a high degree of analytical flexibility.

The conceptual basis of SCA is to identify all of the theoretically justifiable analysis decisions in the garden of forking paths [61] for a given relationship - in this case, dysregulated gaming and well-being - and computing results for all of them. Following Orben and 


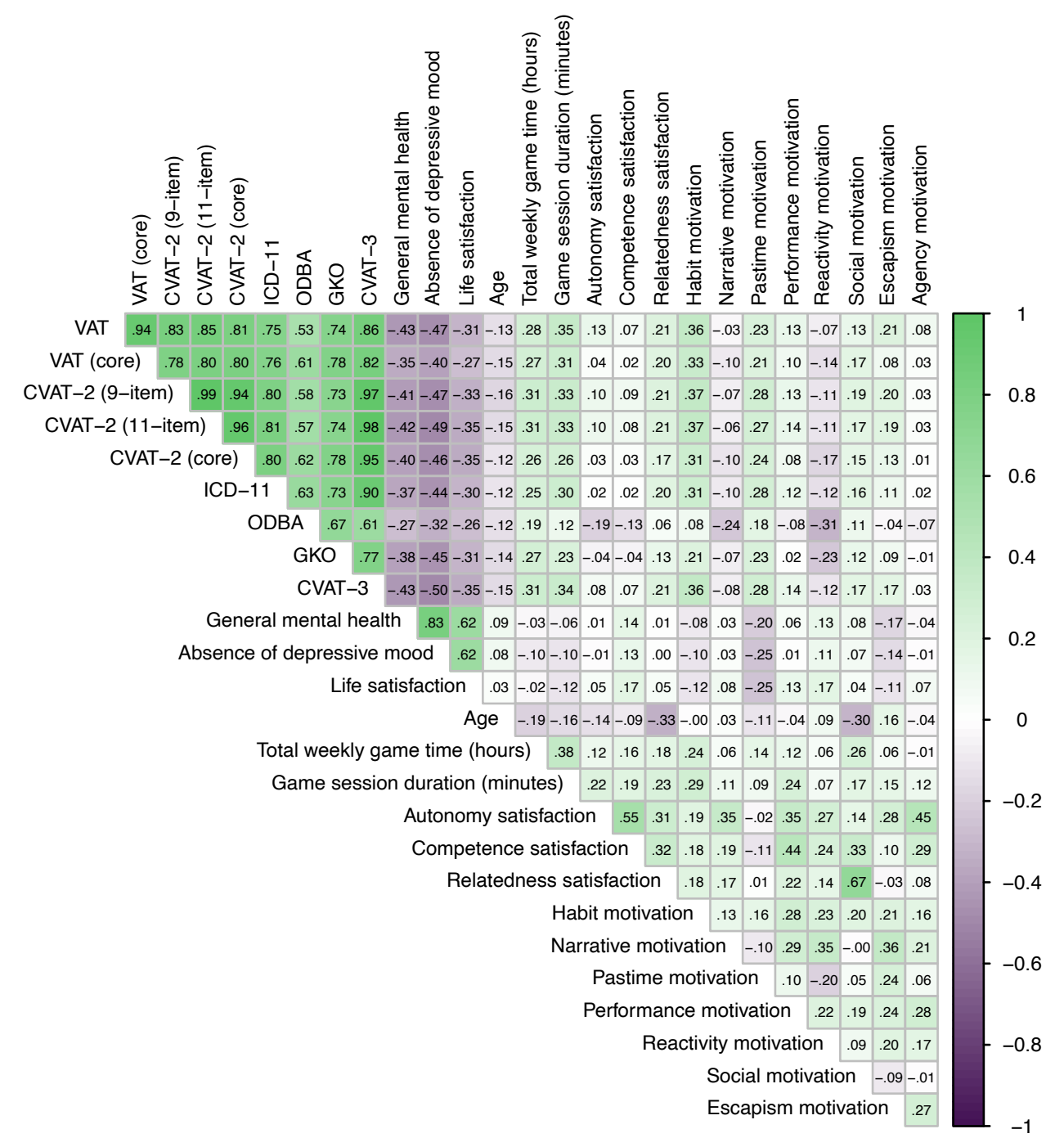

Figure 1. Correlation matrix for dysregulated gaming measures, well-being measures, and covariates. Darker colors are stronger correlations. Significance labels are omitted for readability; all correlations whose absolute values are greater than $r=.16$ are significant at the $p<.001$ level.

Przybylski's [62] study on self-reported quantity of technology use and well-being, we chose to adopt the simplest possible statistical model, linear regression, which meant that the analysis pathways were determined by (1) how to operationalize well-being, (2) how to operationalize dysregulated gaming severity, (3) which covariates to include, and (4) whether to exclude possible outliers.

Inferences are drawn based on the distribution of the results in the specification curve, which may therefore be interpreted as essentially a single test of the relationship in question, in this case between dysregulated gaming and well-being. As we are not interested in rejecting a null hypothesis based on the results of an individual model, we do not correct for multiple tests. It is nonetheless important to note that a certain proportion of models may be expected to be significant even when there is no true effect (or, alternatively, some models may be non-significant even if there is a true effect, depending on the power of the test). 
With our sample of 424 participants, we have $90 \%$ power to detect a standardized regression coefficient of $\beta=.16$ in bivariate linear models (i.e., models with no included covariates).

Mental Well-being. With regard to the first analytical decision, well-being, we identified all three relevant measures as justifiable specifications, namely life satisfaction (Satisfaction With Life scale), general mental health (Mental Health Inventory), and (absence of) depressive mood (Adolescent Depressive Mood scale), leading to 3 specifications.

Gaming Disorder. For operationalizing gaming disorder, we included all 5 original measures in the study (VAT, CVAT-2, ICD-11, ODBA, and GKO), as well as the combined scale CVAT-3. Both the 9- and 11-item versions of the CVAT-2 were considered valid analysis choices. Given the debates identified above around the inclusion of peripheral vs core criteria, we also identified specifications using only core criteria as justifiable. This resulted in a VAT (core) specification composed of 8 items explicitly addressing core criteria as well as a CVAT-2 (core) specification made up of 7 items (see Tables A1 and A2 in the appendix for exact items). The ICD-11, ODBA, and GKO scales each contain 5 or fewer items, of which only one ODBA item is peripheral, and thus separate core criteria operationalizations were not included for those scales. A core criteria version of the CVAT-3 was deemed to be redundant, as it would consist of the CVAT-2 (core) and all four ICD-11 items, and also was not included. This resulted in 9 total specifications for gaming disorder.

Covariates. Finally, we identified a number of possible analytical decisions with regard to control variables. To determine which could be justifiably included, we searched the literature for precedent and included all variables that had previously been associated with increased gaming disorder severity. These included (1) age [e.g., 63], (2) gender [e.g., 64], (3) educational level [e.g., 65], (4/5) average amount of time played during a given session and in an average week [e.g., 66], (6-8) satisfaction of the needs for autonomy, competence, and relatedness during video game play [e.g., 37], and (9-16) the 8 gaming motivations [e.g., 30]. Possible model specifications included models with a single covariate, all 16 covariates together, and no covariates, leading to a total of 18 possible specifications for control variables.

Outliers. Of the 424 participants, 21 were identified as probable outliers based on high reported weekly game time or long average session duration (3 or more standard deviations above the mean, equivalent to 90 weekly hours or 412 minutes played per session). In addition, one participant reported a total weekly gametime of 0 hours. However, given that these participants passed the careless response checks and did not exhibit any other signs of malicious reporting (e.g., uniform or patterned responses) and that the focus of dysregulated gaming research is on extreme behavior, we considered both exclusion or inclusion of the probable outliers as justifiable analysis decisions, and therefore include this as analysis choice within the specification curve. In total, this meant that $3 * 9 * 18 * 2=972$ models were calculated.

\section{Results}

We use R Version 4.0.3 [67] and the R packages dplyr [68], ggplot2 [69], lavaan [70], papaja [71], and specr [72] for our analyses and to generate the manuscript. The data, supplementary materials, as well as all processing and analysis scripts are available on the Open Science Framework (https://osf.io/h9kmv/); the raw data was originally archived on Dataverse (https://doi.org/10.34894/FMR1WG). 
Table 2

Fit indices for each of the 9 dysregulated gaming scale operationalizations

\begin{tabular}{llllcc}
\hline & \multicolumn{1}{c}{$\chi^{2}(\mathrm{df})$} & CFI & RMSEA [90\% CI] & SRMR & McDonald's $\omega_{h}$ \\
\hline VAT & $895.19(77), \mathrm{p}<.001$ & 0.695 & $0.156[0.145,0.167]$ & 0.089 & $.86[0.84,0.89]$ \\
VAT (core) & $64.83(14), \mathrm{p}<.001$ & 0.952 & $0.086[0.058,0.116]$ & 0.044 & $0.83[0.78,0.87]$ \\
CVAT-2 (9-item) & $110.89(27), \mathrm{p}<.001$ & 0.931 & $0.082[0.063,0.101]$ & 0.048 & $0.83[0.80,0.86]$ \\
CVAT-2 (11-item) & $205.58(44), \mathrm{p}<.001$ & 0.904 & $0.089[0.074,0.104]$ & 0.054 & $0.86[0.83,0.88]$ \\
CVAT-2 (core) & $62.84(14), \mathrm{p}<.001$ & 0.949 & $0.087[0.061,0.114]$ & 0.043 & $0.82[0.79,0.86]$ \\
ICD & $3.66(2), \mathrm{p}=.161$ & 0.999 & $0.033[0.000,0.122]$ & 0.014 & $0.83[0.78,0.86]$ \\
ODBA & $6.64(2), \mathrm{p}=.036$ & 0.989 & $0.068[0.000,0.147]$ & 0.026 & $0.63[0.55,0.71]$ \\
GKO & $21.51(5), \mathrm{p}=.001$ & 0.989 & $0.075[0.006,0.135]$ & 0.025 & $0.85[0.80,0.88]$ \\
CVAT-3 & $439.36(90), \mathrm{p}<.001$ & 0.887 & $0.091[0.080,0.102]$ & 0.055 & $0.90[0.88,0.92]$ \\
\hline
\end{tabular}

Note. CFI $=$ Comparative Fit Index, RMSEA $=$ Root Mean Square Error of Approximation, SRMR = Standardized Root Mean Square Residual. Point estimates and confidence intervals for $\omega_{h}$ are calculated using 1000 bias-corrected and accelerated bootstrap samples, as recommended by [54].

\section{Factor Analysis}

First, we briefly present data on the psychometric structure of the dysregulated gaming measures both to give context to the results of the specification curve as well as to evaluate the appropriateness of these scales, some of which are novel, for future use. To do so, we run confirmatory factor analyses using robust maximum likelihood estimation on each of the 9 dysregulated gaming scales as well as compute reliability. While we do not adopt absolute cut-off values, fit indices may be interpreted according to the following benchmarks [73]:

- CFI: $\geq 0.95$ considered good fit, $\geq 0.90$ considered acceptable

- RMSEA $\leq 0.06$ considered good fit $\leq 0.08$ considered acceptable

- SRMR $\leq 0.08$ considered good fit

Results of these analyses are summarized in Table 2. These suggest the strongest fit for the ICD-11 scale. Fit indices indicated good fit for the ODBA scale as well, but with low reliability, which is influenced by the length of the scale but may also be an indication of an insufficiently narrow construct [74]. Results for both the ICD-11 and ODBA scales should be interpreted cautiously, as with only four items per scale the models have only two degrees of freedom, leading to wide confidence intervals for RMSEA. However, evidence suggests that certain fit indices like RMSEA over-reject correctly-specified models with few degrees of freedom [75], and thus we have a reasonable degree of confidence in the performance of these scales.

Fit is somewhat worse but generally acceptable for both versions of the CVAT-2 as well as the CVAT-3, and the results suggest poorest fit for the VAT. The poor fit for the VAT compared to its initial validation study may be in part a function of correlated residuals used in the original factor model; because this study uses mean scores instead of latent factor scores, this is not accounted for here. Fit is drastically improved, however, in the core version of the VAT relative to the full version $(\triangle C F I=0.257 ; \triangle R M S E A=-0.070)$. The same is true to a lesser extent for the CVAT-2 (core) compared to the full version $(\triangle C F I=$ 0.045; $\triangle R M S E A=-0.002)$. Overall, factor analysis results are mixed, with some indices 
like SRMR evidencing good fit for most models, but others like RMSEA suggesting poorer fit. Results from the VAT (full version) should be interpreted with the most caution, while the remainder appear to meet minimum standards of measurement validity.

\section{Specification Curve}

Dysregulated gaming measures. All of the 972 models under investigation yielded significant negative relationships between dysregulated gaming and mental well-being (Figure 2). The median dysregulated gaming coefficient across all models was $\beta=-0.39$, with the median model accounting for $15.9 \%$ of the variance (multiple $R^{2}=0.159$ ). The model with the smallest coefficient regressed ODBA scores onto life satisfaction with all covariates, resulting in an effect size of $\beta=-0.19$ (95\% CI [-0.29, -0.09]; multiple $R^{2}=$ 0.188). The model with the largest coefficient estimate, on the other hand, uses the CVAT-3 as the $x$ variable and depressive mood as the $y$ variable, with habit motivation as a control ( $\beta=-0.54 ; 95 \%$ CI $[-0.63,-0.44]$; multiple $\left.R^{2}=0.246\right)$.

We find substantial overlap in the distribution of estimates across the various dysregulated gaming measures (Figure 3). On average, the VAT, CVAT-2 (11-item) and CVAT-3 predicted the highest amount of variance in well-being among dysregulated gaming specifications (i.e., yielded the largest effect sizes), but distributions for these largely coincide with the remaining measures. This was also the case for the comparison of core and peripheral criteria; data show minimal differences between the core criteria versions of the VAT and CVAT-2 (11-item) and their respective full versions, with the core criteria versions of each producing on average slightly less negative estimates than their core/peripheral counterparts, but with overlapping confidence intervals (Table 3 ).

One scale proved to be an exception; visual inspection of the SCA plot as well as investigation of the effect sizes in Table 3 revealed that the ODBA scale was the dysregulated gaming measure mostly weakly associated with well-being. The range in median point estimates for the 8 other dysregulated gaming measures spanned from -0.44 to -0.36 ( $\Delta \beta=$ 0.08). The difference between the median point estimate for the ODBA scale and its closest other scale, the ICD-11, was 0.09.

\section{Well-being}

The results show that distributions of estimates differ between well-being measures (Figure 3), with depressive mood exhibiting the largest coefficients on average (median $\beta$ $=-0.47,95 \%$ CI $[-0.55,-0.38] ; \min \beta=-0.54,[-0.63,-0.44] ; \max \beta=-0.29,[-0.38,-0.19])$. General mental health showed a slightly weaker relationship (median $\beta=-0.40,95 \%$ CI $[-0.50,-0.31] ; \min =-0.48[-0.58,-0.38] ; \max =-0.24[-0.34,-0.14])$, with life satisfaction having on average the weakest relationship (median $\beta=-0.33,95 \%$ CI $[-0.42,-0.23]$; $\min =$ $-0.41[-0.51,-0.32] ; \max =-0.19[-0.29,-0.09])$.

\section{Decomposed Variance}

To better understand the relative importance of analytical decisions concerning each component of the models (i.e., dependent variable, independent variable, and controls), we conducted a decomposed variance analysis. This method calculates intraclass correlation coefficients using a multilevel model with no fixed effects, but with random effects representing 


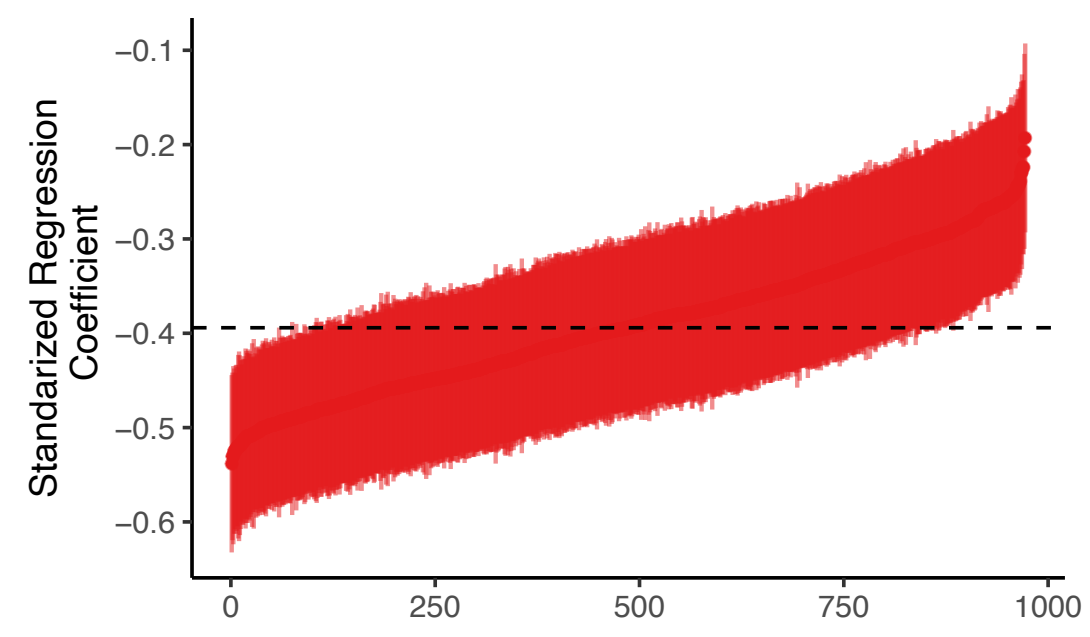

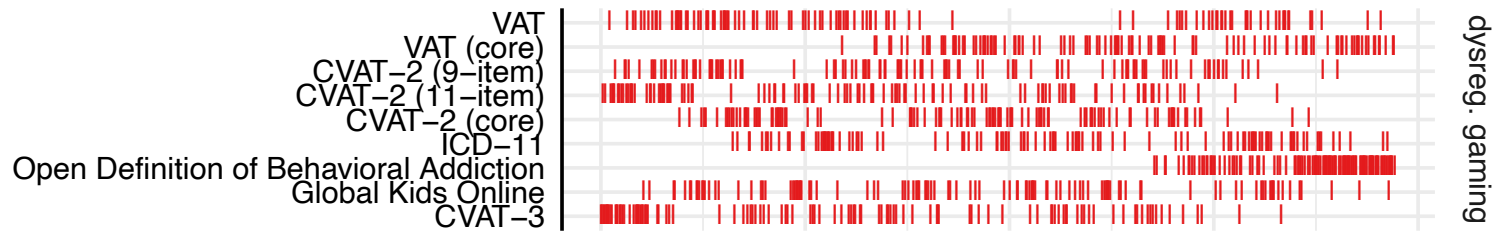
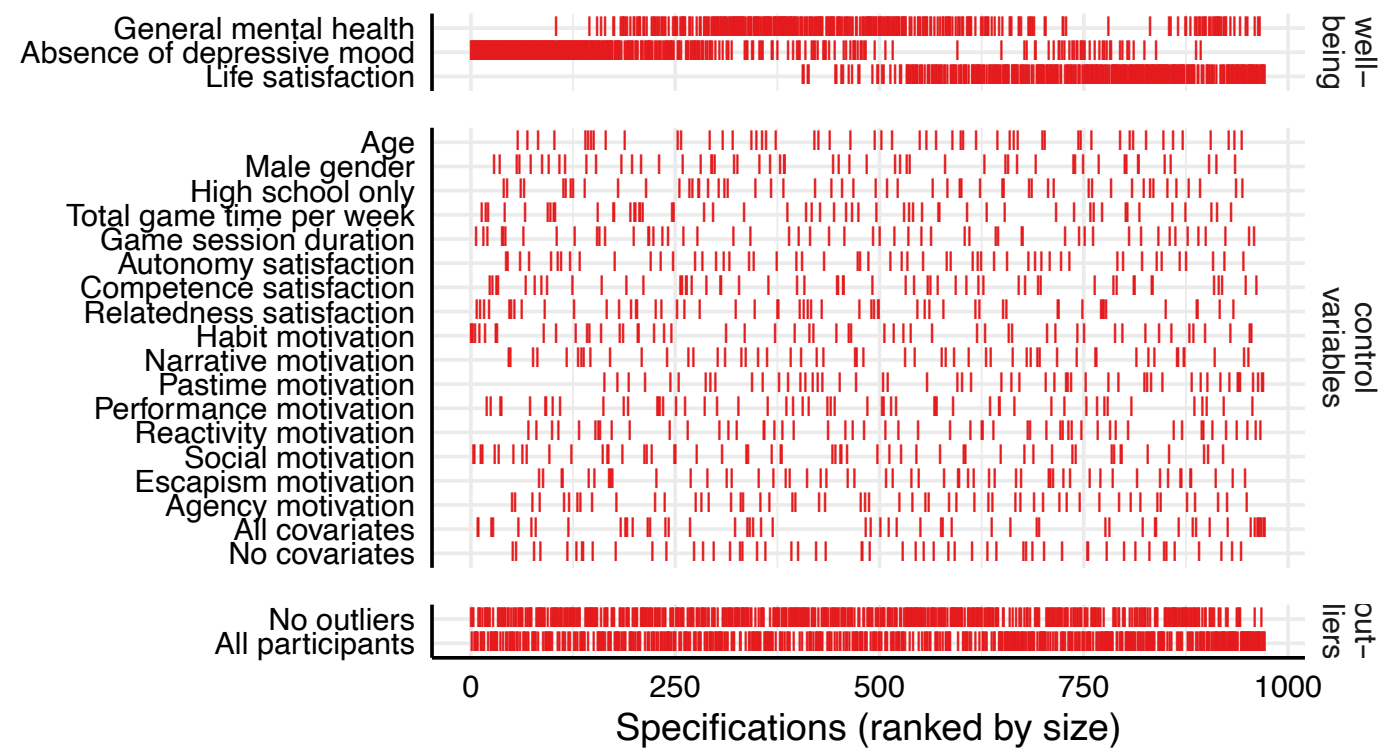

Figure 2. Specification curve results comparing the effect size estimates from each of the possible models. In the top portion of the plot, standardized regression coefficients $(\beta \mathrm{s})$ for dysregulated gaming as a predictor of well-being are ordered by size. Tightly-spaced dark red dots each correspond to the effect size estimate for a single model in which well-being is regressed onto a dysregulated gaming measure and possible covariate(s); light red vertical lines depict the $95 \%$ confidence interval of that estimate. The dashed line represents the median effect size of $\beta=-0.40$. In the bottom portion of the plot, each row depicts the distribution of models in which that variable or subset of the data was part of the analysis; each line represents a single model and is aligned vertically with its corresponding effect size estimate in the top part. All effect sizes were calculated with linear regression models and are reported as standardized beta coefficients. 
Table 3

Summary of linear regression coefficients for each predictor of well-being (dysregulated gaming measures, demographics, and covariates) across all models in which they appear

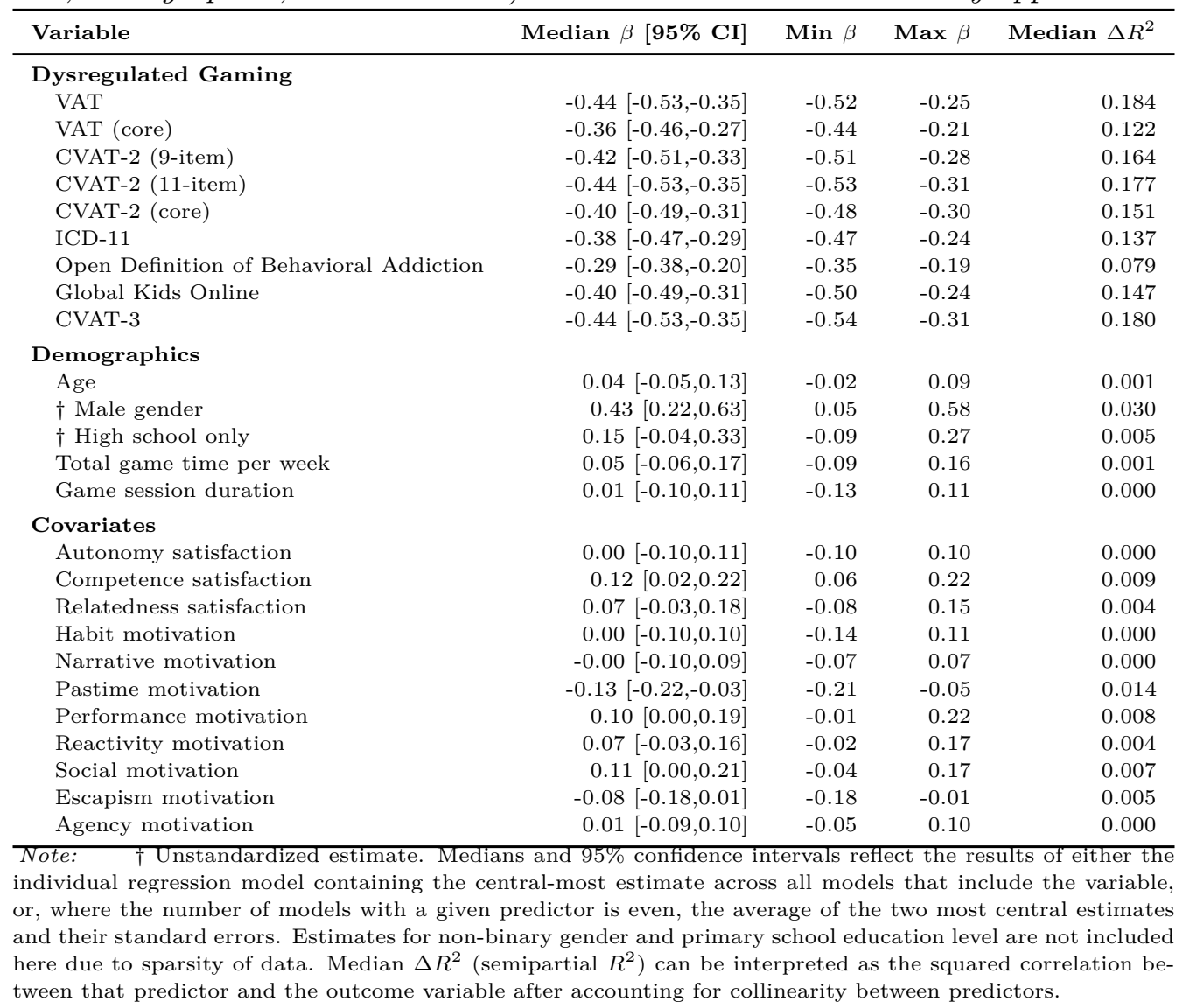

the different analytical choices (a so-called null model). This quantifies the contribution of each class of analysis choice to the total variance in effect sizes observed across the specification curve models [72,see also 76 for details on intraclass coefficients].

Results of the decomposed variance analysis show that the choice of dysregulated gaming measure accounts for $34.8 \%$ of the variance in coefficients (Figure 4). The choice of well-being outcome, on the other hand, was more important, accounting for $55.7 \%$ of the variance. Analytical decisions regarding the covariates and the inclusion of outliers were the least impactful, at only $2.3 \%$ and $2.0 \%$ of the variance, respectively.

As noted above, results indicated that the ODBA scale was unique among the 9 dysregulated gaming specifications. Thus, for comparison, we repeated the same SCA but omitted the ODBA, and conducted the decomposed variance analysis again. With the ODBA omitted, analytical decisions involving the remaining 8 dysregulated gaming specifications accounted for just $8.6 \%$ of the variance, with well-being now accounting for $82.2 \%$, showing that the ODBA adds substantial additional variance to the specification curve when included and confirming its divergent behavior. 


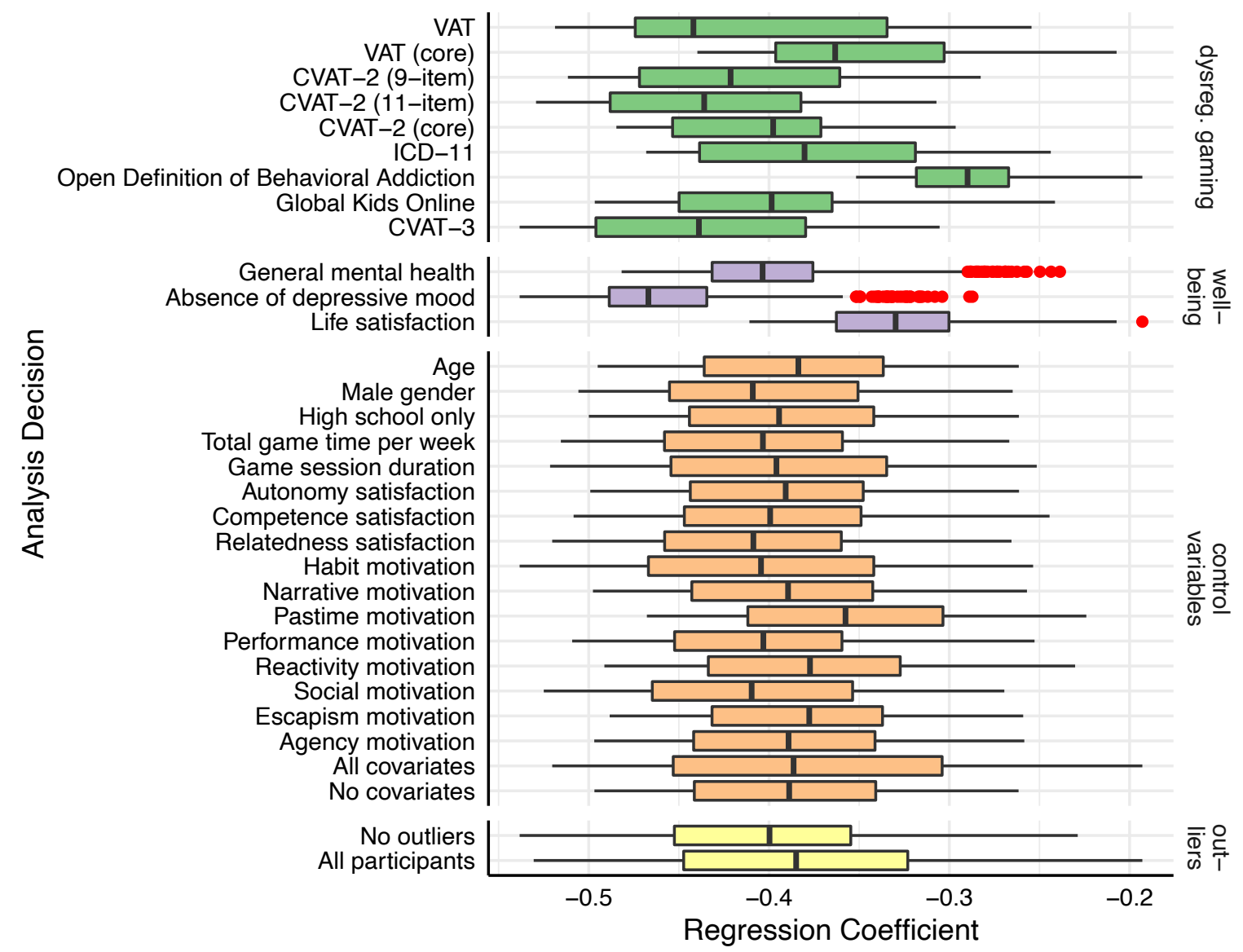

Figure 3. Box plots corresponding to the bottom half of Figure 2. Each box plot shows the distribution of regression coefficients for the primary relationship between dysregulated gaming and well-being for all SCA models adopting that analytical decision. Vertical lines represent the median effect size for that analysis choice, while red dots indicate outliers whose effect sizes in the SCA were at least $\pm 1.58 \times I Q R / \sqrt{n}$.

\section{Covariates}

Table 3 show that the majority of covariates account for very little unique variance. Of the control variables, being male was most strongly linked with well-being (median unstandardized coefficient $b=0.43,95 \%$ CI $[0.22,0.63]$ ). Being male was more strongly associated with general mental health and absence of depressive mood (median $b \mathrm{~s}=0.46$ and 0.45 , respectively) than with life satisfaction (median $b=0.14$ ).

The 8 gaming motivations subscales and three need satisfaction in games subscales had small and inconsistent effects (median $\beta \mathrm{s} \leq 0.13$; median $\Delta R^{2} \mathrm{~s} \leq 0.014$ ). Total weekly game time, while exhibiting moderate zero-order correlations with dysregulated gaming severity and a weak zero-order correlation with absence of depressive mood $(r=-0.097,95 \%$ CI $[-0.190,-0.002], p=0.046)$, was not correlated with either life satisfaction or general mental health, and was a negligible independent predictor of well-being in the regression models (median $\Delta R^{2}=0.001$ ). 


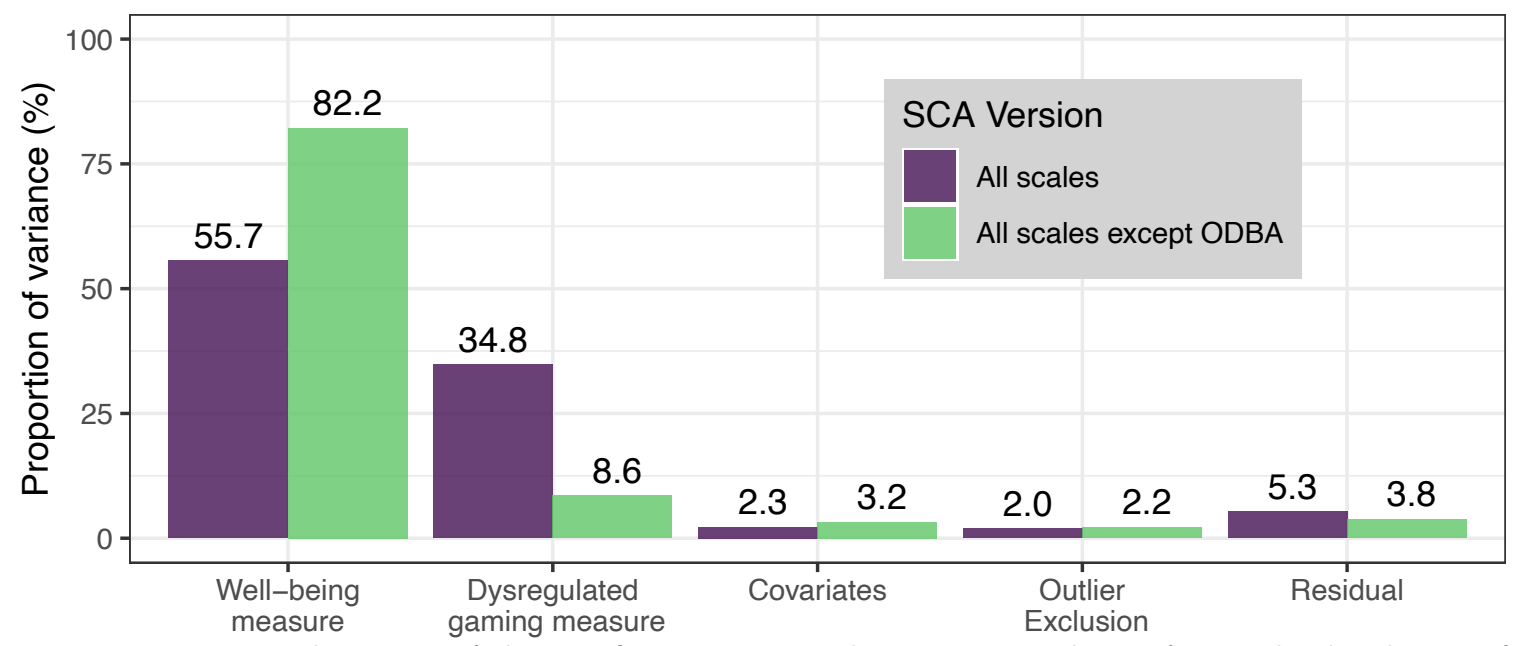

Figure 4. Decomposed variance of the specification curve analyses. Variance here refers to the distribution of regression coefficients for dysregulated gaming as a predictor of well-being across the 972 SCA models (i.e., variance leading to the observed effect size range of -.19 to -.54$)$. Bars indicate the percentage of this variance that is explained by analytical decisions involving each component of the models (summing to 100\%). Purple bars are results from the first SCA with all 9 possible operationalizations of dysregulated gaming, while green bars reflect results of the same analysis conducted after removing the ODBA as a specification after data indicated that this measure was anomalous.

\section{Item-level analyses}

To better understand the finding that the VAT (core) and CVAT-2 (core) specifications diverged minimally from their core and peripheral counterparts, we conducted a final exploratory SCA, this time using individual scale items as the possible predictors of wellbeing. We chose the CVAT-2 (11-item) and the ICD-11 scales for this to fully capture the criteria included in the the DSM-5 and ICD-11.

Results show that all individual items are significantly associated with decreased well-being in the majority of models, but that the strength of the relationship varies widely between criteria (Table 4). Despite being a peripheral criterion, the largest single-item predictor of decreased well-being was the CVAT-2's mood modification/escapism item, whose median effect size was $\beta=-0.46$ (95\% CI [-0.55, -0.37], $\left.\Delta R^{2}=0.201\right)$. The items with the weakest association with well-being, on the other hand, were tolerance (median $\beta=-0.17$ $95 \%$ CI [-0.27, -0.07], $\Delta R^{2}=0.028$ ), continuation despite problems ("Did you play games even though you knew this was causing problems with your family, friends, at work, or at school?") $(\beta=-0.2195 \%$ CI [-0.30, -0.11$\left.], \Delta R^{2}=0.042\right)$, and preoccupation $(\beta=-0.21$ $95 \%$ CI $\left.[-0.31,-0.11], \Delta R^{2}=0.040\right)$.

\section{Discussion}

\section{Dysregulated gaming and well-being}

The results of the specification curve analysis show a consistent negative relationship between dysregulated gaming severity and mental well-being. Regardless of how one operationalizes dysregulated gaming, well-being, outliers, and covariates, the effect remains statistically significant. Relative to the minimal existing data on the role of analytical flexibility in studies on digital media, the distribution of effect sizes in our study forms a comparably narrow range. For example, [62] find in one of their three datasets that analytical 
Table 4

Effect sizes from specification curve using single-item indicators of dysregulated gaming severity as explanatory variables. Items are ordered from largest to smallest median $\beta$.

\begin{tabular}{lrrrrl}
\hline Variable & Item label & Median $\beta[\mathbf{9 5 \%}$ CI] & Min $\beta$ & Max $\beta$ & Median $\Delta R^{2}$ \\
\hline Mood modification/Escapism & CVAT-2 \#5 & $-0.46[-0.55,-0.37]$ & -0.52 & -0.28 & 0.201 \\
Problems (health) & CVAT-2 \#11 & $-0.36[-0.45,-0.27]$ & -0.40 & -0.30 & 0.130 \\
Loss of interests & CVAT-2 \#6 & $-0.35[-0.44,-0.26]$ & -0.40 & -0.28 & 0.122 \\
Continuation despite problems (ICD) & ICD-11 \#3 & $-0.34[-0.43,-0.25]$ & -0.40 & -0.21 & 0.112 \\
Problems persist > 1 year (ICD) & ICD-11 \#4 & $-0.32[-0.41,-0.23]$ & -0.41 & -0.21 & 0.098 \\
Loss of control (ICD) & ICD-11 \#1 & $-0.30[-0.39,-0.20]$ & -0.35 & -0.11 & 0.084 \\
Loss of control & CVAT-2 \#3 & $-0.29[-0.39,-0.20]$ & -0.32 & -0.10 & 0.084 \\
Lying/deception & CVAT-2 \#7 & $-0.28[-0.38,-0.19]$ & -0.32 & -0.13 & 0.079 \\
Withdrawal & CVAT-2 \#2 & $-0.28[-0.38,-0.19]$ & -0.35 & -0.12 & 0.075 \\
Loss of interests (ICD) & ICD-11 \#2 & $-0.28[-0.37,-0.18]$ & -0.37 & -0.19 & 0.073 \\
Craving & CVAT-2 \#10 & $-0.27[-0.36,-0.17]$ & -0.34 & -0.19 & 0.069 \\
Problems (work/social) & CVAT-2 \#9 & $-0.23[-0.32,-0.13]$ & -0.32 & -0.16 & 0.049 \\
Preoccupation & CVAT-2 \#4 & $-0.21[-0.31,-0.11]$ & -0.25 & -0.04 & 0.040 \\
Continuation despite problems & CVAT-2 \#8 & $-0.21[-0.30,-0.11]$ & -0.29 & -0.16 & 0.042 \\
Tolerance & CVAT-2 \#1 & $-0.17[-0.27,-0.07]$ & -0.24 & -0.11 & 0.028 \\
\hline
\end{tabular}

flexibility in the relationship between technology use and well-being can lead to effect size estimates ranging from approximately $\beta=-.90$ to $\beta=.05$, a total range of .95 , and that approximately $20 \%$ of models yield non-significant effects despite a large sample size and high precision. In our study, we find a total range in effect sizes of 0.35 with all models yielding significant results, providing evidence that dysregulated gaming is more robustly related to well-being and is less subject to the influence of analytical flexibility than research on screen time, a topic known to have particular measurement challenges (e.g., [77]).

The data indicate, however, that dysregulated gaming is not uniformly associated with different aspects of well-being (with choice of well-being measure accounting for $82.2 \%$ of the variance between models, Figure 4). Dysregulated gaming was most strongly associated with greater depressive mood, followed by decreased general mental health, and least strongly with lower life satisfaction. This suggests that there may be variation in the relationship between dysregulated gaming and well-being both at the individual level and across constructs at the population level. While it remains unclear which aspects of well-being are most likely to be linked with dysregulated use and the factors that may underlie this, our findings mirror a recent review article which finds evidence that "digital technology use has stronger effects on short-term markers of hedonic well-being (e.g., negative affect) than long-term measures of eudaimonic well-being (e.g., life satisfaction)" [78, pg. 135].

Despite some differences in dysregulated gaming's relationship with general mental health, depressive mood, and life satisfaction, all effects were relatively large in size, ranging from $\beta=-0.54$ to $\beta=-0.19$ with a median of -0.39 . Effect sizes are difficult to directly interpret, and may be best understood in relation to other, related effects. A full comparison of dysregulated gaming, technology use and well-being measures is outside the scope of this study, and is made more difficult by the fact that a large portion of the published literature has dichotomized participants into 'non-IGD' and 'probable IGD' groups; these are analyzed with logistic regressions that cannot be straightforwardly compared to the linear regression models used here. However, a few examples may be illustrative.

The results presented here diverge somewhat from an early meta-analysis of problematic 
gaming and mental health, which found only a small correlation between problematic gaming and decreased mental health of $R^{2}=0.036$ (95\% CI [.017, .058]), and an $R^{2}$ of 0.068 (95\% CI $[.027, .130])$ among studies that used core criteria only [79]. Similarly, we find a larger association than a more recent meta-analysis [80], which reports a correlation between gaming disorder and psychological well-being of $r=-.146\left(R^{2}=-.021\right)$ across 66 studies. The effect sizes in the current work broadly align with some other non-meta-analytic studies, however; one study found that gaming disorder accounted for $20 \%$ of the variance in loneliness and $22 \%$ of the variance in depression, slightly higher than both the zero-order correlations and partial $R^{2}$ values reported here [40].

It is critical to note that the relationship between dysregulated gaming severity and well-being described here cannot be interpreted as causal. While we find relatively strong associations in this study, these can be contrasted with longitudinal studies that can offer causal evidence, the results of which have not been consistent. Scharkow and colleagues [14], for example, found little to no evidence of an effect of problematic gaming on life satisfaction in a two-year longitudinal study. In a two-year study of problematic gaming in Singapore, on the other hand, dysregulated gaming severity at time 1 was associated with both depression $(\beta=.37)$ and anxiety $(\beta=.29)$ two years later; the authors do not, however, report causal effects in the opposite direction (i.e., depression on subsequent dysregulated gaming) [8]. Another study found that a gaming disorder classification at time 1 predicted emotional distress and hyperactivity one year later; these effects were smaller, however, than that of hyperactivity on subsequent gaming disorder [81]. These comparisons are limited in scope, however, as longitudinal data and gold-standard causal inference remain severely lacking in the field [82].

In sum, we find that one can expect certain well-being outcomes-possibly those related to hedonic well-being - to be more strongly linked with dysregulated gaming than others. Well-being outcomes therefore cannot and should not be straightforwardly substituted for one another. Further investigations using additional aspects well-being (e.g., anxiety, self-esteem, social health) and other functional outcomes (e.g., work/academic performance, physical health) may help to identify the aspects of a person's life that are most likely to be negatively linked to dysregulated gaming, and whether this may be moderated by personality factors. This may in turn help with identification of dysregulation, the development of adaptive coping strategies, and the provision of effective clinical treatment where necessary.

\section{Dysregulated gaming measure selection and validity}

While we find evidence of meaningful differences in effect size depending on the selected well-being measure, the choice of dysregulated gaming measures introduced minimal variance. With the exception of the scale based on the Open Definition of Behavioral Addiction (ODBA), results showed that the other 8 scale specifications converge upon similar associations with decreased well-being, that this is true even for shorter scales, and that it remains true even for scales with weaker model fit. Thus, we do not conclude that any of the scales used here are more predictive of decreased well-being than others.

The reasons underlying the anomalous behavior of the ODBA are not clear, but appear to be driven in part by one item which stands out conceptually among all of the scale items, namely 'the time you spend on games is a conscious choice.' This assesses the role of self-reflection in gaming and is not typically found among dysregulated gaming measures, 
and is indeed the item that loads most poorly onto its hypothesized latent factor $(\lambda=0.28)$. More work is necessary to operationalize the definition put forth in the ODBA [53] and to understand the relationship between non-reflective or low self-awareness game use and well-being outcomes.

Despite repeated calls for consensus and unity in the assessment of dysregulated gaming, measurement tools continue to proliferate [17]. The evidence presented here indicates that measures may be largely convergent in their relationship with the psychosocial and functional outcomes in which we are ultimately interested (i.e., in terms of concurrent criterion validity). We suggest that time and resources may be better spent on topics like harmonization of measurement, comorbidity, the ontology and temporal stability of dysregulation, and treatment efficacy, rather than continued validation of new or existing scales used for cross-sectional studies and non-clinical populations.

\section{Core vs peripheral criteria}

Contrary to expectations, the two scales assessing only core criteria differed only slightly and non-significantly in their association with well-being from the scales assessing both core and peripheral criteria. This finding diverges somewhat from previous results [e.g., 79], showing that scales including peripheral criteria as defined here may still be meaningfully associated with decreased well-being. However, the core and peripheral scales did not account for more variance than the core criteria scales alone. We interpret these results to indicate that although the inclusion of peripheral criteria does not add significant amounts of noise such that the relationship between dysregulated gaming and well-being is obscured, neither does it add meaningfully to our ability to predict the negative outcomes investigated here, and may simply add to participant burden.

To better understand this finding, we investigated the relationships between individual criteria and well-being. Some peripheral items followed the expected pattern; tolerance and preoccupation, which have been criticized in previous work [24,25,83], were found to account for minimal variance in well-being. However, the results for the CVAT-2's mood modification/escapism item were contrary to expectations and showed that mood modification, despite being a peripheral criterion, was the single item most strongly associated with decreased well-being.

One possible explanation for this is that the mood modification item may not only be assessing the extent to which people play games to escape negative moods or the difficulties of day-to-day life, but rather the presence of negative mood and difficulties in day-to-day life in the first place. When looking at dysregulated gaming and well-being or functional impairment, this would therefore mean that a portion of the outcome is included as a predictor. At the moment, this is a speculative explanation and requires nuanced (and ideally within-person) analyses showing an association between escapism and negative affect after controlling for dysregulated gaming. Were this confound to be confirmed, however, this would have significant implications for both the DSM- 5 criteria as well as for the validity of many existing measurement tools. Prominent scales like the IGDS-SF9 [84] and IGD-9 [85] include items like 'Do you play in order to temporarily escape or relieve a negative mood (e.g., helplessness, guilt, anxiety)?' and these items may contribute to inflated prevalence estimates of gaming disorder.

Given the wide range of biological, psychological and ecological factors that can con- 
tribute to the development of dysregulated behavior, some previous research on problematic phone use and problem gambling has adopted a "pathways" approach, which describes different subgroups for whom behavioral patterns may be similar, but with distinct underlying developmental process having led to the dysregulated behavior [86,87]. Blaszczynski and Nower [86] outline a distinction between behaviorally conditioned problem gamblers and emotionally vulnerable problem gamblers for whom gambling 'is viewed as a means of producing emotional escape through the effect of dissociation on mood alteration and narrowed attention' (p. 493), with the latter group also potentially influenced by neurological and neurochemical factors that increase their susceptibility to dysregulated behavior. In the context of games, it is possible that using games as a coping mechanism for problems in one's life is a separable phenomenon from both non-problematic high game engagement and less-comorbid dysregulated gaming. Lee and colleagues [88] advocate for this type of distinction as well; their model of gaming disorder heterogeneity identifies impulsive/aggressive, emotionally vulnerable, socially conditioned, and not otherwise specified as possible sub-types of the condition.

We note although we do not find evidence between core and peripheral scales in terms of (concurrent) criterion validity, our results do support a psychometric distinction between interference (core) and engagement (peripheral) criteria. Model fit for the the VAT (core) and the CVAT-2 (core) are greatly improved relative to the full versions, indicating that the full versions of those scales are not unidimensional. We advise researchers to be cautious if using the VAT or CVAT-2 for cross-sectional research (i.e., where scores are assumed to represent a single latent construct) and either conduct their own factor analyses before interpreting results, or to understand them as comprising a formative rather than reflective construct [89]. The remaining operationalizations, including the core versions of the VAT and CVAT-2, ICD-11, GKO, and to a slightly lesser extent CVAT-3, appear to be justifiable candidates for use in survey-based dysregulated gaming research.

We argue that criteria for dysregulated gaming should be meaningfully associated with functional and psychosocial well-being outcomes and as parsimonious as possible. Our results suggest that a subset of peripheral criteria, notably tolerance, may have small or practically insignificant associations with well-being, and that escapism's large association with well-being may be the result of a confound. Future work in this area will benefit from comparisons of core and peripheral criteria scales using other outcome measures (e.g., academic/career performance, physical health, relationship quality) as well as more in-depth investigations of the criterion validity of individual items.

\section{Role of covariates}

Overall, the inclusion or exclusion of covariates had a negligible impact on our results. The covariate with the largest impact was gender; being male was associated with higher general mental health and less depressive mood symptoms, but was only weakly related to life satisfaction in our sample. This is consistent with previous research finding higher rates of depression in women during both adolescence and adulthood [90,91].

Turning to motivational styles, which have received significant research attention as possible predictors of dysregulated gaming, we find that three motivations - habit, escapism, and pastime - were zero-order correlated with dysregulated gaming measures, and that two of these (escapism and pastime) were correlated with well-being as well, but in the regression 
models independently predicted very little of the variance in well-being. This is in line with previous evidence [e.g., 27], and shows that these motivations may help us to understand the underlying causes of dysregulated gaming. However, similar to mood modification items in dysregulated gaming measures (see above), escapism motivation items may in part assess the presence of negative mood and difficulties from which to escape. We caution against treating motivational profiles as risk factors, given the lack of clarity regarding causality, but encourage further work to determine why some players with escapist motivations may report lower well-being, while others do not.

We find that the presence of need satisfaction in games is a negligible predictor of well-being, and that competence satisfaction in games is even weakly positively associated with well-being on average. This suggests that need satisfaction in video games is not a meaningful risk factor for dysregulated gaming by itself. We note, however, that selfdetermination theory contrasts between need satisfaction and need frustration [92], and emerging evidence supports a relationship between need frustration in daily life beyond video games (i.e., a persistent sense of lacking control in one's life, ineffectiveness in one's activities, and/or social disconnectedness) and dysregulation [36,37]. While we did not account for daily or in-game need frustration in the current paper, this is a promising area for future work, and may help us understand both the interplay of environmental factors and behavior, as well as the developmental course of dysregulation.

Finally, we find no evidence that weekly gametime is meaningfully associated with well-being. Results show weak and non-significant zero-order correlations between dysregulated gaming symptom endorsement and well-being, and across 108 multiple regression models that included weekly gametime as a covariate, none of its coefficients were statistically significant. In other words, after accounting for dysregulated gaming, the relationship between self-reported quantity of game use on well-being ranges from slightly positive to slightly negative, with the median regression model showing a minute positive relationship. These results are comparable and underscore those of Orben and Przbylski [62], whose specification curve analysis of technology use and well-being in adolescents found that the median effect sizes from three large-scale datasets were negligible in size $(\beta \mathrm{s}=-0.04,-0.01,-0.03$; partial $\left.R^{2} \mathrm{~S}=-0.001,<0.001,0.004\right)$. In the context of games specifically, other work has also found small and non-significant effects of self-reported gameplay frequency on psychosocial health [93].

In other words, weekly playtime is weakly correlated with dysregulated gaming severity, and dysregulated gaming severity is moderately correlated with well-being outcomes, but the absence of a clear relationship between weekly playtime and well-being directly suggests that other factors besides quantity of use are more important for understanding problematic patterns of play. Thus, we argue that research attention should be focused on the contextual, motivational, and personality factors that may differentiate game use that positively affects players' lives to the rarer cases in which game use is associated with negative consequences, rather than amount of playtime.

\section{Limitations}

As with the majority of the studies in the field, this study is limited by overall low rates of dysregulated gaming symptom endorsement. Response patterns and associations in non-clinical samples are likely to differ from clinical populations, and the same is true of 
samples of people who play games (as gathered here) versus the population at large. The results of this study should also not be assumed to generalize to more severe dysregulation, different well-being constructs, or other cultures.

This study is also limited by the measures included, with some having been newly developed for this study (ICD-11, ODBA, GKO, and CVAT-3), one exhibiting mediocre model fit here despite previous evidence of validity (VAT), and others adapted for use outside of their original clinical context (CVAT-2). The choice of included measures was influenced by a few factors. First, survey design decisions were driven by the primary goal of the data collection, namely to develop and validate the CVAT-3 for use as a self-test for Dutch and Flemish speakers, as opposed to an explicit effort to compare the most commonly-used gaming disorder scales. Second, Dutch language scales were used, which are neither as widespread nor extensively validated as English scales. Finally, the high participant burden of the survey led to the necessity of limiting the length of any newly-developed measures. Results for the measures with weaker model fit should be interpreted cautiously, and further work will be necessary to justify their inclusion in future studies.

The survey design is a further limitation; a fixed order was used to prevent repetitive measures being placed together and to avoid long series of negatively-oriented measures. Manual inspection of the data showed minimal signs of straight-lining; where this did occur, these were typically the same participants who failed one or both attention checks, justifying the decision to exclude these participants. We did not observe any systematic change in mean scores or decreasing within-scale variance with measures later in the survey. Nonetheless, (conceptual) replications of the current study and further work on the possibility of order effects would both be valuable.

Finally, the majority of the measures used here do not have empirically-grounded diagnostic thresholds. Therefore, it was not possible to assess the relationship between well-being and a gaming disorder diagnosis or classification according to each scale; instead, we focused on severity as continuous variable, i.e. the mean score of gaming disorder measures. While diagnosis based on scale scores are controversial and diverge from clinical appraisals [94], the DSM-5 explicitly states a threshold of 5 out of 9 endorsed criteria. Future work would be well-served to compare the relationship between well-being, clinician-rated dysregulated gaming, and frequently-used measures like the IGDS-SF9 [84] that specify a proposed diagnostic cut-off point.

\section{Conclusion}

In this study, we used specification curve analysis to investigate the strength of the relationship between dysregulated gaming and well-being. We find that analytical decisions can result in effect size estimates ranging from -0.54 to -0.19 , but that the direction and significance of the relationship is consistent across all justifiable models. We contextualize this as a comparatively narrow range, and find that while one dysregulated gaming measure was anomalous, only a small portion of the variance in these effect sizes was attributable to the difference between the remaining 8 dysregulated gaming measures. Rather, differences were primarily a result of choice of well-being measure, with life satisfaction most weakly associated with dysregulated play and depressive mood most strongly. Our results indicate that peripheral criteria, while not adding significant amounts of noise to the association between dysregulated gaming and well-being, also do not strengthen this relationship. Mood 
modification items and related escapism motivations may assess the presence of problems or negative moods in a person's life, and not simply the use of games to cope with problems or moods. Weekly playtime was not meaningfully associated with well-being. We argue for a wider comparison of well-being outcomes, a focus on identifying the most parsimonious list of meaningful gaming disorder criteria, and harmonization of measures that may ultimately differ little from each other in survey-based research.

\section{Data Availability}

All data, code, and materials associated with this project are available on the Open Science Framework http://doi.org/10.17605/osf.io/H9KMV.

\section{Funding}

The first author was supported by the EPSRC Centre for Doctoral Training in Intelligent Games \& Games Intelligence (IGGI) [EP/S022325/1]. The second author received funding from the ZonMw project [\#531004006, Preventieprogramma 5].

\section{Competing Interests}

The authors have no conflicts of interest to declare.

\section{Contributions}

AVR designed the initial study and collected the data. NB and AVR conducted data analysis. NB wrote the first draft of the manuscript. Both authors contributed equally to revision and approve the final manuscript.

1. Van Rooij AJ, Kardefelt-Winther D. Lost in the chaos: Flawed literature should not generate new disorders. Journal of Behavioral Addictions. 2017;6(2):128-32.

2. American Psychiatric Association, editor. Diagnostic and statistical manual of mental disorders: DSM-5. 5th ed. Washington, D.C: American Psychiatric Association; 2013.

3. World Health Organization. International classification of diseases for mortality and morbidity statistics (ICD-11). 11th ed. 2018.

4. Aarseth E, Bean AM, Boonen H, Colder Carras M, Coulson M, Das D, et al. Scholars' open debate paper on the World Health Organization ICD-11 Gaming Disorder proposal. Journal of Behavioral Addictions. 2017;6(3):267-70.

5. Billieux J, King DL, Higuchi S, Achab S, Bowden-Jones H, Hao W, et al. Functional impairment matters in the screening and diagnosis of gaming disorder: Commentary on: Scholars' open debate paper on the World Health Organization ICD-11 Gaming Disorder proposal (Aarseth et al.). Journal of Behavioral Addictions. 2017 Sep;6(3):285-9.

6. Van Rooij AJ, Ferguson CJ, Colder Carras M, Kardefelt-Winther D, Shi J, Aarseth E, et al. A weak scientific basis for gaming disorder: Let us err on the side of caution. Journal of Behavioral Addictions. 2018;7(1):1-9.

7. Granic I, Lobel A, Engels RCME. The benefits of playing video games. American Psychologist. 2014;69(1):66-78.

8. Gentile DA, Choo HC, Liau A, Sim T, Li D, Fung D, et al. Pathological video game use among youths: A two-year longitudinal study. Pediatrics. 2011 Feb;127(2):e319-29. 
Kim NR, Hwang SS-H, Choi J-S, Kim D-J, Demetrovics Z, Kir'aly O, et al. Characteristics and Psychiatric Symptoms of Internet Gaming Disorder among Adults Using Self-Reported DSM-5 Criteria. Psychiatry Investigation. 2016 Jan;13(1):58-66.

10. Hawi NS, Samaha M, Griffiths MD. Internet gaming disorder in Lebanon: Relationships with age, sleep habits, and academic achievement. Journal of Behavioral Addictions. 2018 Mar;7(1):70-8.

11. Henchoz Y, Studer J, Deline S, N'Goran AA, Baggio S, Gmel G. Video gaming disorder and sport and exercise in emerging adulthood: A longitudinal study. Behavioral Medicine. 2016 Apr;42(2):105-11.

12. Bargeron AH, Hormes JM. Psychosocial correlates of internet gaming disorder: Psychopathology, life satisfaction, and impulsivity. Computers in Human Behavior. 2017 Mar;68:388-94.

13. Müller KW, Janikian M, Dreier M, Wölfling K, Beutel ME, Tzavara C, et al. Regular gaming behavior and internet gaming disorder in European adolescents: Results from a cross-national representative survey of prevalence, predictors, and psychopathological correlates. European Child \& Adolescent Psychiatry. 2015 May;24(5):565-74.

14. Scharkow M, Festl R, Quandt T. Longitudinal patterns of problematic computer game use among adolescents and adults-a 2-year panel study: Longitudinal patterns of problematic gaming. Addiction. 2014 Nov;109(11):1910-7.

15. Przybylski AK, Weinstein N. Investigating the motivational and psychosocial dynamics of dysregulated gaming: Evidence from a preregistered cohort study. Clinical Psychological Science. 2019;

16. Charlton JP, Danforth IDW. Distinguishing addiction and high engagement in the context of online game playing. Computers in Human Behavior. 2007 May;23(3):1531-48.

17. King DL, Chamberlain SR, Carragher N, Billieux J, Stein D, Mueller K, et al. Screening and assessment tools for gaming disorder: A comprehensive systematic review. Clinical Psychology Review. 2020 Feb;101831.

18. Brunborg GS, Hanss D, Mentzoni RA, Pallesen S. Core and Peripheral Criteria of Video Game Addiction in the Game Addiction Scale for Adolescents. Cyberpsychology, Behavior, and Social Networking. 2015 May;18(5):280-5.

19. Griffiths MD. The role of context in online gaming excess and addiction: Some case study evidence. International Journal of Mental Health and Addiction. 2010 Jan;8(1):119-25.

20. Van Rooij AJ, Schoenmakers TM, Vermulst AA, Van Den Eijnden RJJM, Van De Mheen D. Online video game addiction: Identification of addicted adolescent gamers: Online video game addiction. Addiction. 2011 Jan;106(1):205-12.

21. Deleuze J, Long J, Liu T-Q, Maurage P, Billieux J. Passion or addiction? Correlates of healthy versus problematic use of videogames in a sample of French-Speaking regular players. Addictive Behaviors. 2018 Jul;82:114-21.

22. Skoric MM, Teo LLC, Neo RL. Children and Video Games: Addiction, Engagement, and Scholastic Achievement. CyberPsychology \& Behavior. 2009 Oct;12(5):567-72.

23. Charlton JP. A factor-analytic investigation of computer 'addiction' and engagement. British Journal of Psychology. 2002 Aug;93(3):329-44.

24. Kir'aly O, Sleczka P, Pontes HM, Urb'an R, Griffiths MD, Demetrovics Z. Validation of the Ten-Item Internet Gaming Disorder Test (IGDT-10) and evaluation of the nine DSM-5 Internet Gaming Disorder criteria. Addictive Behaviors. 2017 Jan;64:253-60.

25. Deleuze J, Nuyens F, Rochat L, Rothen S, Maurage P, Billieux J. Established risk factors for addiction fail to discriminate between healthy gamers and gamers endorsing DSM-5 Internet gaming disorder. Journal of Behavioral Addictions. 2017;6(4):1-9.

26. Billieux J, Flayelle M, Rumpf H-J, Stein DJ. High involvement versus pathological involvement in video games: A crucial distinction for ensuring the validity and utility of gaming disorder. Current Addiction Reports. 2019 Sep;6(3):323-30.

27. Hilgard J, Engelhardt CR, Bartholow BD. Individual differences in motives, preferences, and pathology in video games: The gaming attitudes, motives, and experiences scales (GAMES). Frontiers in Psychology. 2013;4. 
28. Yee N. Motivations for play in online games. CyberPsychology \& Behavior. 2006;9(6):772-5.

29. Kuss DJ, Louws J, Wiers RW. Online gaming addiction? Motives predict addictive play behavior in massively multiplayer online role-playing games. Cyberpsychology, Behavior, and Social Networking. 2012 Sep;15(9):480-5.

30. Billieux J, Van der Linden M, Achab S, Khazaal Y, Paraskevopoulos L, Zullino D, et al. Why do you play World of Warcraft? An in-depth exploration of self-reported motivations to play online and in-game behaviours in the virtual world of Azeroth. Computers in Human Behavior. 2013 Jan;29(1):103-9.

31. Männikkö N, Billieux J, Nordström T, Koivisto K, Kääriäinen M. Problematic Gaming Behaviour in Finnish Adolescents and Young Adults: Relation to Game Genres, Gaming Motives and Self-Awareness of Problematic Use. International Journal of Mental Health and Addiction. 2017 Apr;15(2):324-38.

32. Ryan RM, Deci EL. Self-determination theory and the facilitation of intrinsic motivation, social development, and well-being. American Psychologist. 2000;55(1):68-78.

33. Ryan RM, Deci EL. Self-determination theory: Basic psychological needs in motivation, development, and wellness. New York: Guilford Press; 2017.

34. Ryan RM, Rigby CS, Przybylski A. The motivational pull of video games: A self-determination theory approach. Motivation and Emotion. 2006 Dec;30(4):344-60.

35. Peng W, Lin J-H, Pfeiffer KA, Winn B. Need satisfaction supportive game features as motivational determinants: An experimental study of a self-determination theory guided exergame. Media Psychology. 2012;15(2):175-96.

36. Mills DJ, Milyavskaya M, Mettler J, Heath NL. Exploring the pull and push underlying problem video game use: A Self-Determination Theory approach. Personality and Individual Differences. 2018;135:176-81.

37. Allen JJ, Anderson CA. Satisfaction and frustration of basic psychological needs in the real world and in video games predict internet gaming disorder scores and well-being. Computers in Human Behavior. 2018 Jul;84:220-9.

38. Bender PK, Gentile DA. Internet gaming disorder: Relations between needs satisfaction in-game and in life in general. Psychology of Popular Media Culture. 2019 Jan;9(2):266-78.

39. Montag C, Schivinski B, Sariyska R, Kannen C, Demetrovics Z, Pontes HM. Psychopathological Symptoms and Gaming Motives in Disordered GamingA Psychometric Comparison between the WHO and APA Diagnostic Frameworks. Journal of Clinical Medicine. 2019 Oct;8(10):1691.

40. Pontes HM, Schivinski B, Sindermann C, Li M, Becker B, Zhou M, et al. Measurement and Conceptualization of Gaming Disorder According to the World Health Organization Framework: The Development of the Gaming Disorder Test. International Journal of Mental Health and Addiction. 2019 Jun;

41. Meade AW, Craig SB. Identifying careless responses in survey data. Psychological Methods. 2012 Sep;17(3):437-55.

42. Dunn TJ, Baguley T, Brunsden V. From alpha to omega: A practical solution to the pervasive problem of internal consistency estimation. British Journal of Psychology. 2014 Aug;105(3):399-412.

43. Revelle W, Zinbarg RE. Coefficients Alpha, Beta, Omega, and the glb: Comments on Sijtsma. Psychometrika. 2009 Mar;74(1):145-54.

44. Ware Jr. JE, Sherbourne CD. The MOS 36-Item Short-Form Health Survey (SF-36): I. Conceptual Framework and Item Selection. Medical Care. 1992;30(6):12.

45. Cuijpers P, Smits N, Donker T, ten Have M, de Graaf R. Screening for mood and anxiety disorders with the five-item, the three-item, and the two-item Mental Health Inventory. Psychiatry Research. 2009 Aug;168(3):250-5.

46. Diener E, Emmons RA, Larsen RJ, Griffin S. The Satisfaction With Life Scale. Journal of Personality Assessment. 1985 Feb;49(1):71-5.

47. Kandel DB. Epidemiology of Depressive Mood in Adolescents: An Empirical Study. Archives of General Psychiatry. 1982 Oct;39(10):1205. 
48. Van Rooij AJ, Schoenmakers TM, van den Eijnden RJJM, Vermulst AA, van de Mheen D. Video Game Addiction Test: Validity and Psychometric Characteristics. Cyberpsychology, Behavior, and Social Networking. 2012 Sep;15(9):507-11.

49. Meerkerk G-J, Van Den Eijnden RJJM, Vermulst AA, Garretsen HFL. The Compulsive Internet Use Scale (CIUS): Some Psychometric Properties. CyberPsychology \& Behavior. 2009 Feb;12(1):1-6.

50. Van Rooij AJ, Schoenmakers TM, van de Mheen D. Clinical validation of the C-VAT 2.0 assessment tool for gaming disorder: A sensitivity analysis of the proposed DSM-5 criteria and the clinical characteristics of young patients with 'video game addiction.' Addictive Behaviors. 2017 Jan;64:26974 .

51. UNICEF Office of Research-Innocenti, London School of Economics and Political Science, EU Kids Online Network. Global Kids Online: Child and parent questionnaire [Internet]. 2016. Available from: http://globalkidsonline.net/tools/survey/

52. Billieux J, Van Rooij AJ, Heeren A, Schimmenti A, Maurage P, Edman J, et al. Behavioural Addiction Open Definition 2.0-using the Open Science Framework for collaborative and transparent theoretical development: Commentaries. Addiction. 2017 Oct;112(10):1723-4.

53. Kardefelt-Winther D, Heeren A, Schimmenti A, Van Rooij AJ, Maurage P, Carras M, et al. How can we conceptualize behavioural addiction without pathologizing common behaviours? Addiction. 2017 Oct;112(10):1709-15.

54. Kelley K, Pornprasertmanit S. Confidence intervals for population reliability coefficients: Evaluation of methods, recommendations, and software for composite measures. Psychological Methods. 2016;21(1):69-92.

55. De Grove F, Cauberghe V, Van Looy J. Development and Validation of an Instrument for Measuring Individual Motives for Playing Digital Games. Media Psychology. 2016 Jan;19(1):101-25.

56. De Grove F, Breuer J, Hsueh Hua Chen V, Quandt T, Ratan R, Van Looy J. Validating the Digital Games Motivation Scale for Comparative Research Between Countries. Communication Research Reports. 2017 Jan;34(1):37-47.

57. Bandura A. Social foundations of thought and action: A social cognitive theory. Englewood Cliffs, N.J: Prentice-Hall; 1986. (Prentice-Hall series in social learning theory).

58. Chen B, Vansteenkiste M, Beyers W, Boone L, Deci EL, Van der Kaap-Deeder J, et al. Basic psychological need satisfaction, need frustration, and need strength across four cultures. Motivation and Emotion. 2015 Apr;39(2):216-36.

59. Haerens L, Aelterman N, Vansteenkiste M, Soenens B, Van Petegem S. Do perceived autonomysupportive and controlling teaching relate to physical education students' motivational experiences through unique pathways? Distinguishing between the bright and dark side of motivation. Psychology of Sport and Exercise. 2015 Mar;16:26-36.

60. Simonsohn U, Simmons JP, Nelson LD. Specification curve: Descriptive and inferential statistics on all reasonable specifications. SSRN Electronic Journal. 2015;

61. Gelman A, Loken E. The Statistical Crisis in Science: Data-dependent analysisa "garden of forking paths" explains why many statistically significant comparisons don't hold up. American Scientist. 2014;102(6):460.

62. Orben A, Przybylski AK. The association between adolescent well-being and digital technology use. Nature Human Behaviour. 2019 Feb;3(2):173-82.

63. Wittek CT, Finseraas TR, Pallesen S, Mentzoni RA, Hanss D, Griffiths MD, et al. Prevalence and Predictors of Video Game Addiction: A Study Based on a National Representative Sample of Gamers. International Journal of Mental Health and Addiction. 2016 Oct;14(5):672-86.

64. Desai RA, Krishnan-Sarin S, Cavallo D, Potenza MN. Video game playing in high school students: Health correlates, gender differences and problematic gaming. Pediatrics. 2010 Dec;126(6):e1414-24.

65. Mallorquí-Bagué N, Fernández-Aranda F, Lozano-Madrid M, Granero R, Mestre-Bach G, Baño M, et al. Internet gaming disorder and online gambling disorder: Clinical and personality correlates. Journal of Behavioral Addictions. 2017 Dec;6(4):669-77. 
66. Rehbein F, Kliem S, Baier D, Mößle T, Petry NM. Prevalence of internet gaming disorder in German adolescents: Diagnostic contribution of the nine DSM-5 criteria in a state-wide representative sample: Internet gaming disorder in adolescents. Addiction. 2015 May;110(5):842-51.

67. R Core Team. R: A language and environment for statistical computing [Internet]. Vienna, Austria: R Foundation for Statistical Computing; 2019. Available from: https://www.R-project.org/

68. Wickham H, François R, Henry L, Müller K. Dplyr: A grammar of data manipulation [Internet]. 2020. Available from: https://CRAN.R-project.org/package=dplyr

69. Wickham H. ggplot2: Elegant graphics for data analysis [Internet]. Springer-Verlag New York; 2016. Available from: https://ggplot2.tidyverse.org

70. Rosseel Y. lavaan: An R package for structural equation modeling. Journal of Statistical Software [Internet]. 2012;48(2):1-36. Available from: http://www.jstatsoft.org/v48/i02/

71. Aust F, Barth M. papaja: Create APA manuscripts with R Markdown [Internet]. 2020. Available from: https://github.com/crsh/papaja

72. Masur PK, Scharkow M. Specr: Statistical functions for conducting specification curve analyses (version 0.1.1) [Internet]. 2019. Available from: https://github.com/masurp/specr

73. $\mathrm{Hu} \mathrm{L}$, Bentler PM. Cutoff criteria for fit indexes in covariance structure analysis: Conventional criteria versus new alternatives. Structural Equation Modeling: A Multidisciplinary Journal. 1999 Jan;6(1):1-55.

74. Stanley LM, Edwards MC. Reliability and Model Fit. Educational and Psychological Measurement. 2016 Dec;76(6):976-85.

75. Kenny DA, Kaniskan B, McCoach DB. The Performance of RMSEA in Models With Small Degrees of Freedom. Sociological Methods \& Research. 2015 Aug;44(3):486-507.

76. Hox JJ, Moerbeek M, Schoot R van de. Multilevel analysis: Techniques and applications. 2018.

77. Ellis DA, Davidson BI, Shaw H, Geyer K. Do smartphone usage scales predict behavior? International Journal of Human-Computer Studies. 2019 Oct;130:86-92.

78. Dienlin T, Johannes N. The impact of digital technology use on adolescent well-being. Dialogues in Clinical Neuroscience. 2020;22(2):135-42.

79. Ferguson CJ, Coulson M, Barnett J. A meta-analysis of pathological gaming prevalence and comorbidity with mental health, academic and social problems. Journal of Psychiatric Research. 2011 Dec;45(12):1573-8.

80. Cheng C, Cheung MW-L, Wang H. Multinational comparison of internet gaming disorder and psychosocial problems versus well-being: Meta-analysis of 20 countries. Computers in Human Behavior. 2018 Nov;88:153-67.

81. Wartberg L, Kriston L, Zieglmeier M, Lincoln T, Kammerl R. A longitudinal study on psychosocial causes and consequences of Internet gaming disorder in adolescence. Psychological Medicine. 2019 Jan;49(2):287-94.

82. Mihara S, Higuchi S. Cross-sectional and longitudinal epidemiological studies of Internet gaming disorder: A systematic review of the literature: Review of epidemiological studies of IGD. Psychiatry and Clinical Neurosciences. 2017 Jul;71(7):425-44.

83. King DL, Delfabbro PH. Defining tolerance in Internet Gaming disorder: Isn't it time?: Letters to the Editor. Addiction. 2016 Nov;111(11):2064-5.

84. Pontes HM, Griffiths MD. Measuring DSM-5 internet gaming disorder: Development and validation of a short psychometric scale. Computers in Human Behavior. 2015 Apr;45:137-43.

85. Lemmens JS, Valkenburg PM, Gentile DA. The Internet Gaming Disorder Scale. Psychological Assessment. 2015 Jun;27(2):567-82.

86. Blaszczynski A, Nower L. A pathways model of problem and pathological gambling. Addiction. 2002 May;97(5):487-99. 
87. Billieux J. Problematic Use of the Mobile Phone: A Literature Review and a Pathways Model. Current Psychiatry Reviews. 2012 Oct;8(4):299-307.

88. Lee S-Y, Lee HK, Choo H. Typology of Internet gaming disorder and its clinical implications: Typology of IGD. Psychiatry and Clinical Neurosciences. 2017 Jul;71(7):479-91.

89. Van Rooij AJ, Van Looy J, Billieux J. Internet Gaming Disorder as a formative construct: Implications for conceptualization and measurement: IGD as a formative construct. Psychiatry and Clinical Neurosciences. 2017 Jul;71(7):445-58.

90. Nolen-Hoeksema S. Sex differences in unipolar depression: Evidence and theory. Psychol Bull. 1987;101(2):259-82.

91. Petersen AC, Sarigiani PA, Kennedy RE. Adolescent depression: Why more girls? Journal of Youth and Adolescence. 1991 Apr;20(2):247-71.

92. Vansteenkiste M, Ryan RM. On psychological growth and vulnerability: Basic psychological need satisfaction and need frustration as a unifying principle. Journal of Psychotherapy Integration. 2013;23(3):263-80.

93. Lobel A, Engels RCME, Stone LL, Burk WJ, Granic I. Video gaming and children's psychosocial wellbeing: A longitudinal study. Journal of Youth and Adolescence. 2017 Apr;46(4):884-97.

94. Jeong H, Yim HW, Lee S-Y, Lee HK, Potenza MN, Kwon J-H, et al. Discordance between selfreport and clinical diagnosis of Internet gaming disorder in adolescents. Scientific Reports. 2018 Dec;8(1):10084. 


\section{Appendix}

List of item wordings for each unique scale in the study. Endorsement percentages refer to the proportion of respondents that answered either 'agree' or 'strongly agree' to each item ('disagree' or 'strongly disagree' for reversed scored items). Endorsement percentages are provided for context only; dichotomizing responses on an ordinal scale is a controversial practice. 
Table A1

Items Wordings for the Video Game Addiction Test (van Rooij et al., 2012)

\begin{tabular}{|c|c|c|c|c|c|}
\hline $\begin{array}{l}\text { Label in } \\
\text { data }\end{array}$ & Construct & English wording & Dutch wording & Core or peripheral & $\begin{array}{r}\text { Percent } \\
\text { Endorsed }\end{array}$ \\
\hline vat1 & Loss of control & $\begin{array}{l}\text { You regularly find it } \\
\text { difficult to stop } \\
\text { gaming }\end{array}$ & $\begin{array}{l}\text { Je vindt het } \\
\text { regelmatig moeilijk om } \\
\text { met gamen te stoppen }\end{array}$ & peripheral & 14.6 \\
\hline vat2 & $\begin{array}{l}\text { Loss of control } \\
\text { (failed attempts } \\
\text { to stop) }\end{array}$ & $\begin{array}{l}\text { You often continue to } \\
\text { play games, despite } \\
\text { your intention to stop }\end{array}$ & $\begin{array}{l}\text { Je gaat vaak langer } \\
\text { door met gamen, } \\
\text { terwijl je je had } \\
\text { voorgenomen om te } \\
\text { stoppen }\end{array}$ & core & 30.9 \\
\hline vat3 & $\begin{array}{l}\text { Conflict } \\
\text { (interpersonal) }\end{array}$ & $\begin{array}{l}\text { Others (e.g., parents } \\
\text { or friends) repeatedly } \\
\text { say you should spend } \\
\text { less time on games }\end{array}$ & $\begin{array}{l}\text { Anderen (bijv. ouders } \\
\text { of vrienden) zeggen } \\
\text { steeds dat je minder } \\
\text { zou moeten gamen }\end{array}$ & core & 17.2 \\
\hline vat4 & $\begin{array}{l}\text { Behavioral } \\
\text { salience } \\
\text { (preference) }\end{array}$ & $\begin{array}{l}\text { You often prefer to } \\
\text { game instead of } \\
\text { spending time with } \\
\text { others }\end{array}$ & $\begin{array}{l}\text { Je gaat vaak liever } \\
\text { gamen dan dat je je } \\
\text { tijd met anderen } \\
\text { doorbrengt }\end{array}$ & peripheral & 21.2 \\
\hline vat5 & Problems (health) & $\begin{array}{l}\text { You regularly do not } \\
\text { get enough sleep } \\
\text { because of gaming }\end{array}$ & $\begin{array}{l}\text { Je komt regelmatig } \\
\text { slaaptekort door het } \\
\text { gamen }\end{array}$ & core & 11.6 \\
\hline vat6 & $\begin{array}{l}\text { Preoccupation } \\
\text { (cognitive } \\
\text { salience) }\end{array}$ & $\begin{array}{l}\text { You often think about } \\
\text { gaming, even when } \\
\text { you cannot play }\end{array}$ & $\begin{array}{l}\text { Je bent vaak in } \\
\text { gedachten bezig met } \\
\text { games, ook als je niet } \\
\text { kunt spelen }\end{array}$ & peripheral & 23.6 \\
\hline vat7 & $\begin{array}{l}\text { Preoccupation } \\
\text { (cognitive } \\
\text { salience) } \\
\end{array}$ & $\begin{array}{l}\text { You look forward to } \\
\text { the next time you can } \\
\text { game }\end{array}$ & $\begin{array}{l}\text { Je verheugt je steeds } \\
\text { op de volgende keer } \\
\text { dat je kunt gamen }\end{array}$ & peripheral & 41.5 \\
\hline vat8 & $\begin{array}{l}\text { Conflict } \\
\text { (intrapersonal) }\end{array}$ & $\begin{array}{l}\text { You regularly think } \\
\text { you should be gaming } \\
\text { less often }\end{array}$ & $\begin{array}{l}\text { Je denkt regelmatig } \\
\text { dat je eigenlijk minder } \\
\text { zou moeten gamen }\end{array}$ & core & 9.7 \\
\hline vat9 & $\begin{array}{l}\text { Loss of control } \\
\text { (failed attempts } \\
\text { to stop) }\end{array}$ & $\begin{array}{l}\text { You tried to spend } \\
\text { less time on gaming, } \\
\text { but were unsuccessful }\end{array}$ & $\begin{array}{l}\text { Je hebt geprobeerd om } \\
\text { minder tijd aan gamen } \\
\text { te besteden en dat is } \\
\text { niet gelukt }\end{array}$ & core & 5.9 \\
\hline vat10 & $\begin{array}{l}\text { Withdrawal } \\
\text { symptoms }\end{array}$ & $\begin{array}{l}\text { You feel restless, } \\
\text { frustrated, or irritated } \\
\text { when you cannot game }\end{array}$ & $\begin{array}{l}\text { Je voelt je telkens rot } \\
\text { wanneer je niet kunt } \\
\text { gamen }\end{array}$ & core & 4.0 \\
\hline vat11 & $\begin{array}{l}\text { Problems } \\
\text { (work/academic) }\end{array}$ & $\begin{array}{l}\text { You rush through your } \\
\text { (home)work to play } \\
\text { games }\end{array}$ & $\begin{array}{l}\text { Je raffelt je (huis)werk } \\
\text { vaak af om te kunnen } \\
\text { gamen }\end{array}$ & core & 9.9 \\
\hline vat12 & $\begin{array}{l}\text { Problems } \\
\text { (work/academic) }\end{array}$ & $\begin{array}{l}\text { You neglect to do your } \\
\text { (home)work because } \\
\text { you prefer to game }\end{array}$ & $\begin{array}{l}\text { Je doet je (huis)werk } \\
\text { regelmatig niet omdat } \\
\text { je wilt gamen }\end{array}$ & core & 9.0 \\
\hline vat13 & $\begin{array}{l}\text { Mood modifica- } \\
\text { tion/escapism }\end{array}$ & $\begin{array}{l}\text { You often game } \\
\text { because you are } \\
\text { feeling down }\end{array}$ & $\begin{array}{l}\text { Je gaat regelmatig } \\
\text { gamen omdat je je rot } \\
\text { voelt }\end{array}$ & peripheral & 25.9 \\
\hline vat14 & $\begin{array}{l}\text { Mood modifica- } \\
\text { tion/escapism }\end{array}$ & $\begin{array}{l}\text { You often game to } \\
\text { forget about a } \\
\text { problem }\end{array}$ & $\begin{array}{l}\text { Je gaat vaak gamen } \\
\text { om een probleem te } \\
\text { vergeten }\end{array}$ & peripheral & 30.2 \\
\hline
\end{tabular}

${ }^{a}$ The canonical version of the VAT is in Dutch. English translations provided are not the result of a formal translation process; these are for reference only and may diverge slightly from the English translations in the original paper (which are also provided for reference and did not undergo a formal translation process) 
Table A2

Items Wordings for the Clinical Video Game Addiction Test 2.0 (van Rooij et al., 2017)

\begin{tabular}{|c|c|c|c|c|c|}
\hline $\begin{array}{l}\text { Label in } \\
\text { data }\end{array}$ & Construct & English wording & Dutch wording & Core or peripheral & $\begin{array}{r}\text { Percent } \\
\text { Endorsed }\end{array}$ \\
\hline cvidat1 & Tolerance & $\begin{array}{l}\text { You continue to spend } \\
\text { more and more time } \\
\text { playing games }\end{array}$ & $\begin{array}{l}\text { Je bent steeds meer } \\
\text { tijd gaan besteden aan } \\
\text { het spelen van games }\end{array}$ & peripheral & 32.5 \\
\hline cvidat2 & $\begin{array}{l}\text { Withdrawal } \\
\text { symptoms }\end{array}$ & $\begin{array}{l}\text { You feel stressed, } \\
\text { annoyed, or angry if } \\
\text { you could not play } \\
\text { games }\end{array}$ & $\begin{array}{l}\text { Je voelt je gestrest, } \\
\text { geïrriteerd, of boos als } \\
\text { je niet kunt gamen }\end{array}$ & core & 8.0 \\
\hline cvidat3 & $\begin{array}{l}\text { Loss of control } \\
\text { (failed attempts } \\
\text { to stop) }\end{array}$ & $\begin{array}{l}\text { You are unable to play } \\
\text { less, even though you } \\
\text { want to }\end{array}$ & $\begin{array}{l}\text { Het lukt je niet om } \\
\text { minder te gaan gamen, } \\
\text { terwijl je dat wel wilt }\end{array}$ & core & 6.4 \\
\hline cvidat4 & $\begin{array}{l}\text { Preoccupation } \\
\text { (cognitive } \\
\text { salience) }\end{array}$ & $\begin{array}{l}\text { You can hardly think } \\
\text { about anything else } \\
\text { than playing games } \\
\text { when you are not } \\
\text { gaming }\end{array}$ & $\begin{array}{l}\text { Je kunt nauwelijks aan } \\
\text { iets anders denken dan } \\
\text { aan gamen als je niet } \\
\text { aan het gamen bent }\end{array}$ & peripheral & 3.8 \\
\hline cvidat5 & $\begin{array}{l}\text { Mood modifica- } \\
\text { tion/escapism }\end{array}$ & $\begin{array}{l}\text { You regularly play } \\
\text { videogames to avoid } \\
\text { thinking about } \\
\text { problems (difficulties) }\end{array}$ & $\begin{array}{l}\text { Je gaat regelmatig } \\
\text { gamen om niet aan } \\
\text { problemen } \\
\text { (moeilijkheden) te } \\
\text { hoeven denken }\end{array}$ & peripheral & 32.1 \\
\hline cvidat6 & $\begin{array}{l}\text { Behavioral } \\
\text { salience (loss of } \\
\text { interests) }\end{array}$ & $\begin{array}{l}\text { You regularly neglect } \\
\text { important activities } \\
\text { because of gaming } \\
\text { (such as social } \\
\text { connections, } \\
\text { school/work, or other } \\
\text { hobbies) }\end{array}$ & $\begin{array}{l}\text { Je verwaarloost } \\
\text { regelmatig belangrijke } \\
\text { zaken of personen om } \\
\text { te kunnen gamen } \\
\text { (zoals sociale } \\
\text { contacten, school, } \\
\text { werk, andere hobby's) }\end{array}$ & core & 11.3 \\
\hline cvidat7 & Lying/deception & $\begin{array}{l}\text { You sometimes lie to } \\
\text { others about the } \\
\text { amount of time you } \\
\text { spend gaming }\end{array}$ & $\begin{array}{l}\text { Je liegt wel eens tegen } \\
\text { anderen over hoe lang } \\
\text { je aan het gamen bent } \\
\text { geweest }\end{array}$ & core & 15.1 \\
\hline cvidat8 & $\begin{array}{l}\text { Continuation } \\
\text { despite problems }\end{array}$ & $\begin{array}{l}\text { You still played games } \\
\text { even though you knew } \\
\text { this was causing } \\
\text { problems with your } \\
\text { family, friends, at } \\
\text { work, or at school }\end{array}$ & $\begin{array}{l}\text { Je hebt toch games } \\
\text { gespeeld terwijl je wist } \\
\text { dat dat problemen gaf } \\
\text { met je familie, } \\
\text { vrienden, werk of op } \\
\text { school }\end{array}$ & core & 23.3 \\
\hline cvidat9 & $\begin{array}{l}\text { Problems } \\
\text { (work/social) }\end{array}$ & $\begin{array}{l}\text { You have had to give } \\
\text { up or greatly reduce } \\
\text { important activities } \\
\text { because of gaming, } \\
\text { such as sports, work, } \\
\text { or interacting with } \\
\text { friends and family }\end{array}$ & $\begin{array}{l}\text { Je hebt door het } \\
\text { gamen belangrijke } \\
\text { activiteiten moeten } \\
\text { opgeven of sterk } \\
\text { verminderen - zoals } \\
\text { sport, werk, of } \\
\text { omgaan met vrienden } \\
\text { en familie }\end{array}$ & core & 7.8 \\
\hline cvidat10 & Craving & $\begin{array}{l}\text { You have a strong } \\
\text { urge (need) to play } \\
\text { video games }\end{array}$ & $\begin{array}{l}\text { Je ervaart vaak sterke } \\
\text { drang (behoefte) om } \\
\text { te gaan gamen }\end{array}$ & peripheral & 14.2 \\
\hline cvidat11 & Problems (health) & $\begin{array}{l}\text { You neglect your own } \\
\text { health because of } \\
\text { gaming (examples: } \\
\text { not getting enough } \\
\text { sleep, showering less } \\
\text { or failing to brush } \\
\text { teeth, eating worse, } \\
\text { drinking insufficiently) }\end{array}$ & $\begin{array}{l}\text { Je verwaarloost je } \\
\text { eigen gezondheid door } \\
\text { het gamen (zoals } \\
\text { slaaptekort, minder } \\
\text { douchen of tanden } \\
\text { poetsen, slechter eten, } \\
\text { niet voldoende } \\
\text { drinken) }\end{array}$ & core & 12.7 \\
\hline
\end{tabular}

a Note: cvidat10 and cvidat11 are only included in the 11-item version of the CVAT-2

a The canonical CVAT variants are in Dutch. English translations provided are not the result of a formal translation process; these are for reference only and may diverge slightly from the English translations in the original paper 
Table A3

Items Wordings for the ICD-11 (novel scale based on definition of Gaming Disorder in the ICD-11; World Health Organization, 2018)

\begin{tabular}{|c|c|c|c|c|c|}
\hline $\begin{array}{l}\text { Label in } \\
\text { data }\end{array}$ & Construct & English wording & Dutch wording & Core or peripheral & $\begin{array}{r}\text { Percent } \\
\text { Endorsed }\end{array}$ \\
\hline icd111 & Loss of control & $\begin{array}{l}\text { You are unable to } \\
\text { control your gaming } \\
\text { (e.g. when you start } \\
\text { gaming, how often and } \\
\text { in which situations). }\end{array}$ & $\begin{array}{l}\text { Het lukt je niet om } \\
\text { gamen onder controle } \\
\text { te houden (bijv. } \\
\text { wanneer je met gamen } \\
\text { begint, hoe vaak je } \\
\text { gamet en in welke } \\
\text { situaties je gaat } \\
\text { gamen) }\end{array}$ & core & 9.7 \\
\hline icd112 & $\begin{array}{l}\text { Behavioral } \\
\text { salience (loss of } \\
\text { interests) }\end{array}$ & $\begin{array}{l}\text { You continuously give } \\
\text { gaming priority over } \\
\text { other hobbies and } \\
\text { daily activities }\end{array}$ & $\begin{array}{l}\text { Je geeft gamen de hele } \\
\text { tijd voorrang boven } \\
\text { andere hobby's en } \\
\text { dagelijkse activiteiten }\end{array}$ & core & 16.0 \\
\hline icd113 & $\begin{array}{l}\text { Continuation } \\
\text { despite problems }\end{array}$ & $\begin{array}{l}\text { You continue gaming } \\
\text { even when this is } \\
\text { creating problems }\end{array}$ & $\begin{array}{l}\text { Je blijft gamen terwijl } \\
\text { dit problemen oplevert }\end{array}$ & core & 8.3 \\
\hline icd114 & $\begin{array}{l}\text { Sustained } \\
\text { problems }\end{array}$ & $\begin{array}{l}\text { Gaming has been } \\
\text { causing you problems } \\
\text { for over a year. }\end{array}$ & $\begin{array}{l}\text { Gamen levert al langer } \\
\text { dan een jaar } \\
\text { problemen op voor je }\end{array}$ & core & 5.4 \\
\hline
\end{tabular}

a The ICD-11 measure was drafted in Dutch based on the English wording of the ICD-11. The English translations are not the result of a formal translation process and are provided simply as a reference for the reader.

Table A4

Items Wordings for the ODBA scale (novel scale based on the Open Definition of Behavioral Addiction; Billieux et al., 2017; Kardefelt-Winther et al., 2017)

\begin{tabular}{|c|c|c|c|c|c|}
\hline $\begin{array}{l}\text { Label in } \\
\text { data }\end{array}$ & Construct & English wording & Dutch wording & Core or peripheral & $\begin{array}{r}\text { Percent } \\
\text { Endorsed }\end{array}$ \\
\hline odba1 & $\begin{array}{l}\text { Problems } \\
\text { (general) }\end{array}$ & $\begin{array}{l}\text { Gaming creates } \\
\text { various problems and } \\
\text { stress in your life }\end{array}$ & $\begin{array}{l}\text { Gamen veroorzaakt } \\
\text { allerlei problemen en } \\
\text { stress in je leven }\end{array}$ & core & 2.8 \\
\hline odba2 & $\begin{array}{l}\text { Sustained } \\
\text { problems }\end{array}$ & $\begin{array}{l}\text { Your gaming has been } \\
\text { causing problems for } \\
\text { you for months, but } \\
\text { you are unable to play } \\
\text { less. }\end{array}$ & $\begin{array}{l}\text { Je hebt al maanden } \\
\text { last van problemen } \\
\text { door het gamen, maar } \\
\text { het lukt je niet om te } \\
\text { minderen }\end{array}$ & core & 1.9 \\
\hline odba3† & Automaticity & $\begin{array}{l}\text { The time you spend } \\
\text { on games is a } \\
\text { conscious choice }\end{array}$ & $\begin{array}{l}\text { Je tijdsbesteding aan } \\
\text { games is een bewuste } \\
\text { keuze }\end{array}$ & peripheral & 4.0 \\
\hline odba $4 \dagger$ & $\begin{array}{l}\text { Problems } \\
\text { (general) }\end{array}$ & $\begin{array}{l}\text { Gaming does not lead } \\
\text { to problems in your } \\
\text { daily life (such as with } \\
\text { school, work, other } \\
\text { interests, friends, or } \\
\text { family) }\end{array}$ & $\begin{array}{l}\text { Gamen leidt niet tot } \\
\text { problemen in je } \\
\text { dagelijks leven (zoals } \\
\text { school, werk, andere } \\
\text { interesses, familie of } \\
\text { vrienden) }\end{array}$ & core & 12.5 \\
\hline
\end{tabular}

Note:

$\dagger$ Reverse scored

${ }^{a}$ The ODBA measure was drafted in Dutch based on the English wording of the ODBA. The English translations are not the result of a formal translation process and are provided simply as a reference for the reader. 
Table A5

Items Wordings for the Global Kids Online scale (http://globalkidsonline.net/tools/survey/)

\begin{tabular}{|c|c|c|c|c|c|}
\hline $\begin{array}{l}\text { Label in } \\
\text { data }\end{array}$ & Construct & English wording & Dutch wording & Core or peripheral & $\begin{array}{r}\text { Percent } \\
\text { Endorsed }\end{array}$ \\
\hline gko1 & Problems (health) & $\begin{array}{l}\text { You have gone without } \\
\text { eating or sleeping } \\
\text { because of the time } \\
\text { you spent on gaming }\end{array}$ & $\begin{array}{l}\text { Je mist maaltijden of } \\
\text { slaap door de tijd die } \\
\text { je met gamen } \\
\text { doorbrengt }\end{array}$ & core & 9.7 \\
\hline gko2 & $\begin{array}{l}\text { Conflict } \\
\text { (interpersonal) }\end{array}$ & $\begin{array}{l}\text { You have experienced } \\
\text { conflicts with family } \\
\text { or friends because of } \\
\text { the time you spent on } \\
\text { gaming }\end{array}$ & $\begin{array}{l}\text { Je hebt conflicten met } \\
\text { familie en vrienden } \\
\text { door de tijd die je aan } \\
\text { het gamen besteedt }\end{array}$ & core & 3.8 \\
\hline gko3 & $\begin{array}{l}\text { Problems } \\
\text { (academic) }\end{array}$ & $\begin{array}{l}\text { Your grades [or work } \\
\text { performance] have } \\
\text { dropped because of } \\
\text { the time I spent on } \\
\text { gaming }\end{array}$ & $\begin{array}{l}\text { Op werk of school } \\
\text { presteer je slechter } \\
\text { door de tijd die je } \\
\text { besteedt aan gamen }\end{array}$ & core & 6.4 \\
\hline gko4 & $\begin{array}{l}\text { Loss of control } \\
\text { (failed attempts } \\
\text { to stop) }\end{array}$ & $\begin{array}{l}\text { You have tried } \\
\text { unsuccessfully to } \\
\text { spend less time on } \\
\text { gaming }\end{array}$ & $\begin{array}{l}\text { Je probeert om minder } \\
\text { tijd te gamen, maar } \\
\text { dit lukt niet }\end{array}$ & core & 4.5 \\
\hline gko5 & $\begin{array}{l}\text { Problems } \\
\text { (general) }\end{array}$ & $\begin{array}{l}\text { You think the amount } \\
\text { of time you spend on } \\
\text { gaming causes } \\
\text { problems for you }\end{array}$ & $\begin{array}{l}\text { Je komt in de } \\
\text { problemen door de } \\
\text { tijd die je aan gamen } \\
\text { besteedt }\end{array}$ & core & 4.5 \\
\hline
\end{tabular}

${ }^{\mathrm{a}}$ In contrast to the above measures, the English language version of the GKO is the canonical one as found in the original survey materials. Dutch wordings were drafted using a triple translate-retranslate-check process. 